(C) The Author(s), 2020. Published by Cambridge University Press on behalf of The Nutrition Society. This is an Open Access article distributed under the terms of the Creative Commons Attribution licence (http://creativecommons.org/licenses/by/4.0/), which permits unrestricted re-use, distribution, and reproduction in any medium, provided the original work is properly cited.

\title{
Healthy eating recommendations: good for reducing dietary contribution to the body's advanced glycation/lipoxidation end products pool?
}

\author{
María Dolores del Castillo ${ }^{1 *}$ (D) , Amaia Iriondo-DeHond ${ }^{1}$, Maite Iriondo-DeHond ${ }^{2}$, Ileana Gonzalez ${ }^{3}$, \\ Alejandra Medrano ${ }^{4}$, Rosana Filip 5 and Jaime Uribarri ${ }^{6}$ \\ ${ }^{1}$ Food Bioscience Group, Department of Bioactivity and Food Analysis, Instituto de Investigación en Ciencias de la \\ Alimentación (CIAL) (CSIC-UAM), Calle Nicolás Cabrera, 9, 28049 Madrid, Spain \\ ${ }^{2}$ Instituto Madrileño de Investigación y Desarrollo Rural, Agrario y Alimentario (IMIDRA), N-II km 38, 28800 Alcalá de Henares, \\ Spain \\ ${ }^{3}$ Biomedical Research Laboratories, Faculty of Medicine, Catholic University of Maule, Av. San Miguel 3605, Talca, Región del \\ Maule, Chile \\ ${ }^{4}$ Departamento de Ciencia y Tecnología de Alimentos, Facultad de Química, Universidad de la República, Avenida Gral. Flores \\ 2124, 11800 Montevideo, Departamento de Montevideo, Uruguay \\ ${ }^{5}$ Department of Pharmacognosy, Institute of Drug Chemistry and Metabolism, School of Pharmacy and Biochemistry, University \\ of Buenos Aires, Junin 954, C1113AAD CABA, Argentina \\ ${ }^{6}$ Department of Medicine, The Icahn School of Medicine at Mount Sinai, 1 Gustave L. Levy Place, New York, NY 10029, USA
}

\section{Abstract}

The present review aims to give dietary recommendations to reduce the occurrence of the Maillard reaction in foods and in vivo to reduce the body's advanced glycation/lipoxidation end products (AGE/ALE) pool. A healthy diet, food reformulation and good culinary practices may be feasible for achieving the goal. A varied diet rich in fresh vegetables and fruits, non-added sugar beverages containing inhibitors of the Maillard reaction, and foods prepared by steaming and poaching as culinary techniques is recommended. Intake of supplements and novel foods with low sugars, low fats, enriched in bioactive compounds from food and waste able to modulate carbohydrate metabolism and reduce body's AGE/ALE pool is also recommended. In conclusion, the recommendations made for healthy eating by the Spanish Society of Community Nutrition (SENC) and Harvard University seem to be adequate to reduce dietary AGE/ALE, the body's AGE/ALE pool and to achieve sustainable nutrition and health.

Key words: Advanced glycation end products: Body: Diet: Healthy nutrition: Maillard reaction: Sustainable health

(Received 27 February 2020; revised 4 May 2020; accepted 19 May 2020; accepted manuscript published online 26 May 2020)

\section{Introduction}

\subsection{Background}

The effect of dietary advanced glycation end products (AGE) and advanced lipoxidation end products (ALE) in health has been a matter of controversy. In 2007, a call for an interdisciplinary debate was made by Professor Henle in the Molecular Nutrition and Food Research Journal to answer the following question: 'are dietary advanced glycation end products a risk to human health?' Henle indicated that physiological consequences of Maillard compounds in foods must be carefully discussed $^{(1)}$. Arguments based on papers published in highimpact journals made Šebeková \& Somoza ${ }^{(2)}$ argue for the motion that dietary AGE are a health risk. On the contrary, Ames ${ }^{(3)}$ provided evidence against the motion. No final conclusion was drawn from the debate, which may indicate the need for a more comprehensive examination on this issue. Although it is now widely recognised that dietary AGE are major contributors to the body's AGE pool, it still remains unclear and controversial whether habitual dietary AGE per se exert negative health effects in humans ${ }^{(4)}$. In the last 20 years, data have been accumulating adding support to the motion that AGE play a significant pathophysiological role, especially in relation to ageing and metabolic disorders ${ }^{(5)}$. Since the accumulation of AGE in the human body appears to be progressive throughout life, a preventive action against glycation by dietary adjustments may be

Abbreviations: AGE, advanced glycation end products; ALE, advanced lipoxidation end products; BSA, bovine serum albumin; CEL, $N^{e}$-(carboxyethyl)lysine; CML, $N$-carboxymethyl lysine; EFSA, European Food Safety Authority; EGCG, (-)epigallocatechin-3-gallate; Glu-AGE, glucose-derived advanced glycation end products; Glycer-AGE, glyceraldehyde-derived advanced glycation end products; GO, glyoxal; HFCS, high-fructose corn syrup; MGH1, methylglyoxal-derived hydroimidazolone 1; MGO, methylglyoxal; RAGE, receptor for advanced glycation end products; SENC, Spanish Society of Community Nutrition (Sociedad Española de Nutrición Comunitaria).

* Corresponding author: María Dolores del Castillo, email mdolores.delcastillo@csic.es 
Fig. 1. Pathways for advanced glycation/lipoxidation end products (AGE/ALE). Structure of the main AGE/ALE reported in foods and in the human body. 3-DG, 3-deoxyglucosulose; $\mathrm{CEL}, \mathrm{N}^{*}$-(carboxyethyl) lysine; $\mathrm{CHO}$, carbohydrate; $\mathrm{CML}, \mathrm{N}$-carboxymethyl lysine; $\mathrm{GO}$, glyoxal; $\mathrm{MG}$-H1, methylglyoxal-derived hydroimidazolone $1 ;$ MGO, methylglyoxal.

warranted $^{(4,6)}$. In 2016, Guilbaud et al. ${ }^{(6)}$ provided dietary strategies to limit the exposure to food AGE. The aim of the present review is to illustrate how the current nutritional recommendations for healthy eating made by the Spanish Society of Community Nutrition (SENC; Sociedad Española de Nutrición Comunitaria) and Harvard University may reduce the body's AGE/ALE pool.

\subsection{What are advanced glycation/lipoxidation end products?}

AGE/ALE are formed in thermally processed foods and in the human body. The Maillard reaction and lipid peroxidation are considered the main pathways of AGE/ALE formation (Fig. 1 $)^{(4)}$. The Maillard reaction, also called non-enzymic browning or glycation, is a series of non-enzymic reactions that take place during heat processing of foods between the carbonyl group of reducing sugars and the free amino groups of amino acids, peptides or proteins. This reaction is of great importance in food chemistry since it has an effect on colour, texture, aroma and flavour precursors in foods ${ }^{(7)}$. AGE are also physiologically formed and accumulated in body fluids and tissues of healthy subjects during ageing and they are increased in patients affected by metabolic disorders, particularly in diabetic patients ${ }^{(4)}$.

The Maillard reaction starts with the condensation of free amino groups of amino acids, peptides or proteins with the carbonyl group of reducing sugars. Lysine and arginine residues of proteins are the most important source of reactive amino groups ${ }^{(8)}$. When the starting sugar is an aldose (for example, glucose), a relatively stable intermediate called an Amadori product (1-amino-1-deoxi-2-ketose) is formed after a loss of a molecule of water, the formation of a Schiff's base and Amadori rearrangement. If the starting sugar is a ketose (for example, fructose), an analogous compound called a Heyns compound is formed. Then, the breakdown of Amadori/Heyns compounds and the formation of highly reactive $\alpha$-dicarbonyl intermediate compounds (for example, glyoxal (GO), methylglyoxal (MGO), diacetyl, 1-deoxyglucosulose or 3-deoxyglucosulose) take place $^{(9)}$. These $\alpha$-dicarbonyls form stable peptide-bound amino acid derivates with lysine and arginine side chains of proteins leading to the formation of AGE such as $\mathrm{N}$-carboxymethyl lysine (CML), $N^{\epsilon}$-(carboxyethyl)lysine (CEL), pentosidine, pyrraline and MGO-derived hydroimidazolone 1 (MGH1) (Fig. 1) $)^{(10,11)}$.

ALE are produced in food and in vivo by carbonyl formed on oxidised lipid and amino compounds ${ }^{(12)}$. The reactive carbonyl species arising from lipid peroxidation are quite heterogeneous and can be divided into three main classes: (1) the $\alpha, \beta$-unsaturated aldehydes (4-hydroxy-2-nonenal and 4-hydroxy hexenal and nonenal and acrolein); (2) di-aldehydes (malondialdehyde and GO); and (3) cheto-aldehydes (MGO, 4-oxo-nonenal and the isoketals also called levuglandins). When these compounds are formed from adducts and cross-links generated by the non-enzymic reaction of dicarbonyls produced by lipid peroxidation, the term ALE is used (Fig. 1) ${ }^{(9)}$. Recently, thirty-five aldehydes and ketones derived from fish oil, the $n-3$ fatty acidrich source, by liquid chromatography-tandem MS (LC-MS/MS) have been described. Authors have found different patterns of carbonyl compound generation between $n-3$ and $n-6$ fatty acids using a lipidomic approach. They pinpointed that GO resulted from oxidation of oleic acids and EPA, while MGO has a low association with fatty acids ${ }^{(13)}$. New dietary ALE (dALE) may be described in the future which may be better chemical indicators of the degree of progress of the reaction during fish processing than those described in Fig. 1 and Table 1.

The Maillard reaction and lipid peroxidation are considered the main sources of AGE/ALE, but other mechanisms such 
Table 1. Nutritional composition and advanced glycation end product (AGE) content of foods and beverages present in the Healthy Eating Pyramid and Plate (Fig. 3)*

AGE (ELISA)

\begin{tabular}{|c|c|c|c|c|c|c|c|c|c|c|}
\hline \multirow[b]{2}{*}{ Food or beverage } & \multicolumn{3}{|c|}{ Carbohydrates } & \multirow[b]{2}{*}{$\begin{array}{c}\text { Total fat } \\
(\mathrm{g} / 100 \mathrm{~g})\end{array}$} & \multirow[b]{2}{*}{ MGO $(\mathrm{nmol} / 100 \mathrm{~g})$} & \multicolumn{3}{|c|}{ AGE (UPLC-MS/MS) $†$} & \multicolumn{2}{|c|}{ AGE (ELISA) } \\
\hline & $\begin{array}{l}\text { Total } \\
(\mathrm{g} / 100 \mathrm{~g})\end{array}$ & $\begin{array}{l}\text { Dietary fibre } \\
(\mathrm{g} / 100 \mathrm{~g})\end{array}$ & $\begin{array}{l}\text { Sugars } \\
(\mathrm{g} / 100 \mathrm{~g})\end{array}$ & & & $\begin{array}{c}\mathrm{CML} \\
(\mathrm{mg} / 100 \mathrm{~g})\end{array}$ & $\begin{array}{c}\text { CEL } \\
(\mathrm{mg} / 100 \mathrm{~g})\end{array}$ & $\begin{array}{c}\text { MGH1 } \\
(\mathrm{mg} / 100 \mathrm{~g})\end{array}$ & CML (kU/100 g)‡ & $\begin{array}{c}\text { Glu-AGE } \\
(\mathrm{kU} / \mathrm{meal}) \S\end{array}$ \\
\hline \multicolumn{11}{|l|}{ Foods } \\
\hline Pasta & 30.86 & 1.80 & 0.56 & 0.93 & n.r. & $0.43-2.30$ & $0.06-0.13$ & $1.41-3.02$ & $112-245$ & 2.97 \\
\hline Whole-grain bread & $42 \cdot 71$ & 6.00 & 4.34 & 3.50 & 4840 & $0.28-0.40$ & $0.21-0.31$ & $3.36-6.01$ & 105 & n.r. \\
\hline Potatoes & $20 \cdot 13$ & 1.80 & 0.91 & $0 \cdot 10$ & n.r. & $0.01-5.7$ & 0.00 & 0.39 & 17 & 4.55 \\
\hline Beans & 21.63 & 5.50 & 0.00 & $5 \cdot 15$ & n.r. & n.r. & n.r. & n.r. & 298 & n.r. \\
\hline Peas & $15 \cdot 63$ & $5 \cdot 50$ & 5.93 & 0.22 & n.r. & 0.05 & 0.06 & $2 \cdot 31$ & n.r. & n.r. \\
\hline Whole-grain flour & 71.97 & $10 \cdot 70$ & 0.41 & 2.50 & n.r. & n.r. & n.r. & n.r. & n.r. & n.r. \\
\hline Brown rice & 31.33 & 1.70 & 0.15 & 0.85 & n.r. & $0.07-2.50$ & $0.02-1.32$ & $1.37-8.59$ & n.r. & n.r. \\
\hline Swiss chard & 3.74 & 1.60 & $1 \cdot 10$ & 0.20 & n.r. & n.r. & n.r. & n.r. & n.r. & 0.74 \\
\hline Broccoli & 6.64 & $2 \cdot 60$ & 1.70 & 0.37 & n.r. & n.r. & n.r. & n.r. & n.r. & \\
\hline Tomato & 3.89 & 1.20 & $2 \cdot 63$ & 0.20 & n.r. & $0.03-1.00$ & 0.01 & 0.11 & 23.00 & \\
\hline Carrot & 9.58 & $2 \cdot 80$ & 4.74 & 0.24 & n.r. & $<30.00$ & n.r. & n.r. & $10 \cdot 00$ & \\
\hline Artichoke & 10.51 & 5.40 & 0.99 & 0.15 & n.r. & n.r. & n.r. & n.r. & n.r. & \\
\hline Pepper & 6.70 & 1.00 & 3.53 & 0.41 & n.r. & n.r. & n.r. & n.r. & n.r. & \\
\hline Onion & $9 \cdot 34$ & $1 \cdot 70$ & $4 \cdot 24$ & $0 \cdot 10$ & n.r. & n.r. & n.r. & n.r. & 36 & \\
\hline Olive oil & 0.00 & 0.00 & 0.00 & $100 \cdot 00$ & $7700-9700$ & 0.00 & 0.00 & 0.00 & $5763-6682$ & n.r. \\
\hline Grapes & $18 \cdot 10$ & 0.90 & 15.48 & $0 \cdot 16$ & n.r. & n.r. & n.r. & n.r. & n.r. & 16.91 \\
\hline Cherries & $16 \cdot 01$ & $2 \cdot 10$ & $12 \cdot 82$ & 0.20 & n.r. & n.r. & n.r. & n.r. & n.r. & \\
\hline Apple & 13.68 & $2 \cdot 30$ & $10 \cdot 37$ & 0.12 & n.r. & 0.00 & 0.00 & 0.20 & 9 & \\
\hline Pear & $15 \cdot 23$ & $3 \cdot 10$ & 9.75 & 0.14 & n.r. & n.r. & n.r. & n.r. & n.r. & \\
\hline Orange & 11.54 & $2 \cdot 40$ & $9 \cdot 14$ & 0.21 & n.r. & 0.00 & 0.00 & 0.05 & 0.00 & \\
\hline Watermelon & 7.55 & 0.40 & $6 \cdot 20$ & 0.15 & n.r. & n.r. & n.r. & n.r. & n.r. & \\
\hline Banana & 22.84 & 2.60 & $12 \cdot 23$ & 0.33 & n.r. & 0.01 & 0.00 & 0.05 & 20 & \\
\hline Cheese & $0.45-2 \cdot 22$ & 0.00 & $0.00-2 \cdot 22$ & $27.44-30.99$ & n.r. & $0.01-169.10$ & $0.01-0.63$ & $0.07-2 \cdot 76$ & $1453-16900$ & n.r. \\
\hline Yogurt & 4.66 & 0.00 & 4.66 & 3.25 & 830 & 0.01 & 0.01 & 0.13 & 3 & $16 \cdot 31$ \\
\hline Eggs & 0.72 & 0.00 & 0.37 & 9.51 & 13670 & $0.06-9.10$ & $0.07-0.08$ & $0.08-0.35$ & 2749 & n.r. \\
\hline Fish & 0.00 & 0.00 & 0.00 & $0.25-5.57$ & $4060-14950$ & $0.05-28.60$ & $0.06-2.82$ & $0.09-10.93$ & $452-4334$ & n.r. \\
\hline Mixed nuts & 22.42 & $6 \cdot 40$ & 5.00 & 53.50 & n.r. & $0.55-1.58$ & $0.82-2 \cdot 22$ & $6.82-12.34$ & $380-11210$ & 0.90 \\
\hline Almonds & 21.55 & 12.50 & 4.35 & 49.93 & n.r. & $0.95-2.28$ & $1.03-4 \cdot 12$ & n.r. & $5473-6650$ & n.r. \\
\hline Chicken & 0.04 & 0.00 & 0.00 & $8 \cdot 10$ & $4170-14440$ & $0.13-0.92$ & $0.14-1.02$ & $0.65-5.16$ & 769-4848 & n.r. \\
\hline Beef & 0.23 & 0.00 & 0.00 & 3.68 & $5860-18150$ & $0.12-2.03$ & $0.23-5.63$ & $0.34-13.48$ & $800-10058$ & n.r. \\
\hline Sausages & 1.29 & 0.00 & 1.29 & 34.50 & n.r. & 0.84 & 1.63 & 3.85 & $1861-5943$ & n.r. \\
\hline Butter & 0.06 & 0.00 & 0.06 & $81 \cdot 11$ & n.r. & $3 \cdot 10-6 \cdot 30$ & 0.00 & 0.00 & 26480 & n.r. \\
\hline Candy & 93.55 & 0.20 & $70 \cdot 00$ & 0.05 & n.r. & 0.03 & 0.02 & 0.11 & $197-3440$ & n.r. \\
\hline Croissants & $45 \cdot 80$ & $2 \cdot 60$ & $11 \cdot 26$ & 21.00 & n.r. & 1.04 & 1.33 & 9.89 & 1113 & n.r. \\
\hline Cake & 61.00 & 0.50 & 36.66 & $2 \cdot 70$ & n.r. & $0.51-1.75$ & $0.23-0.55$ & $2 \cdot 61-5.57$ & $27-1410$ & 28.06 \\
\hline Biscuits & 70.54 & 3.50 & $21 \cdot 16$ & 10.58 & n.r. & $1.03-2.59$ & $0.48-3.42$ & $3.99-36.90$ & $90-3220$ & 4.42 \\
\hline Chips (crisps) & 53.83 & $3 \cdot 10$ & 0.33 & 33.98 & n.r. & $0.14-19.00$ & 0.09 & 1.28 & 2883 & n.r. \\
\hline Beverages & & & & & n.r. & & & & & \\
\hline Tea & 0.00 & 0.00 & 0.00 & 0.00 & n.r. & n.r. & n.r. & n.r. & $0.40-2.00$ & $0.57-13.24$ \\
\hline Coffee & 0.17 & 0.00 & 0.00 & 0.00 & n.r. & 0.00 & 0.01 & 0.24 & $1.60-13.60$ & $0.47-2.50$ \\
\hline Fruit juice & 11.86 & 1.00 & 10.86 & 0.01 & n.r. & 0.00 & 0.00 & 0.05 & $0.00-6.00$ & $15 \cdot 62-31.35$ \\
\hline Milk & 4.46 & 0.00 & 4.46 & 3.46 & 620 & $0 \cdot 25-23 \cdot 10$ & 0.02 & 0.12 & 4.9 & $2 \cdot 20$ \\
\hline Sweetened soft drinks & 10.36 & 0.00 & 9.94 & 0.25 & $33-422$ & 0.00 & 0.00 & 0.00 & $2 \cdot 40-6 \cdot 40$ & 56.67 \\
\hline Unsweetened soft drinks & 0.12 & 0.00 & 0.00 & 0.00 & $13-325$ & n.r. & n.r. & n.r. & $1.20-4.00$ & n.r. \\
\hline
\end{tabular}

UPLC-MS/MS, ultra-performance liquid chromatography-tandem MS; MGO, methylglyoxal; CML, N-carboxymethyl lysine; CEL, $N$-(carboxyethyl)lysine; MGH1, methylglyoxal-derived hydroimidazolone 1; Glu-AGE, glucose-derived AGE (for example, pentosidine); n.r., not reported.

* Data for carbohydrate and fat content were obtained from the National Nutrient Database for Standard Reference Legacy Release of the United States Department of Agriculture (USDA) Agricultural Research Service, while those corresponding to AGE were from + Scheijen et al.(17), $\neq$ Uribarri et al.(32) and § Takeuchi et al (16) 
as auto-oxidation of monosaccharides, high fructose and ascorbic acid levels, and environmental stress (such as drought or excessive light) also contribute to their formation in plants ${ }^{(4)}$. CML is a commonly used marker compound to evaluate both the progress of the Maillard reaction and lipid peroxidation in foods and a biomarker measured in diabetes and $\mathrm{CVD}^{(14,15)}$. Most of the databases of AGE content in foods include information on CML, which makes the comparison of results published in different studies easier. Moreover, the chronic intake of CML leads to an increase in its content in organs and tissues ${ }^{(6)}$. However, other AGE besides CML have been proposed as better chemical indicators in foods such as CEL or MGH1 even when it is hard to find information of their content in foods (Fig. 1 and Table 1) ${ }^{(16,17)}$. The robustness of the methods used for CML analysis is also a matter of controversy. Either liquid chromatography-MS (LC-MS) or ELISA has been widely used to measure this compound. The correlation between values obtained from both methods has been described by different authors and it can be said that, in general, a reasonable relationship between CML determined by ELISA and HPLC electrospray ionisation ion-trap tandem mass spectrometry (HPLC-ESI-ITMS/MS) or ultra-performance liquid chromatography-tandem MS (UPLC-MS/MS) has been established ${ }^{(18,19)}$.

There are several factors that affect the rate of the Maillard reaction such as $\mathrm{pH}$, temperature, water activity and chemical composition of the food system ${ }^{(8)}$. The reaction rate generally increases with $\mathrm{pH}$ and temperature. Water activity (intermediate moisture $=0 \cdot 5-0 \cdot 8$ ) is another important factor influencing the development of the Maillard reaction. The reaction occurs less readily in foods with high water activity due to the dilution of the reactants. However, at low water activity values the mobility of reactants is limited despite their presence at increased concentrations. With regard to the nature of sugars and amino acids, pentoses (for example, ribose) react more readily than hexoses (for example, glucose), which are more reactive than disaccharides (for example, lactose). On the other hand, lysine is the most reactive amino $\operatorname{acid}^{(8)}$.

AGE/ALE (such as CEL and CML) are involved in the pathogenesis of several diseases such as diabetes and its complications, CVD, neurological disorders and normal ageing ${ }^{(20-23)}$. Thus, preventing AGE and ALE formation/accumulation may control significantly the pathogenesis of diabetes complications ${ }^{(5)}$. The inhibition of AGE formation might follow several mechanisms involving, for example, aldose reductase, the inhibition of the formation and scavenging of free radicals by different antioxidant mechanisms, reactive dicarbonyl trapping, sugar autoxidation inhibition and amino group binding ${ }^{(24)}$. AGE formation may also be inhibited by modulating the glycaemic response through partially inhibiting digestive enzymes such as $\alpha$-amylase, $\beta$-glucosidase, sucrase, and delay sugar transport across the intestinal barrier ${ }^{(25,26)}$. The search for natural products that can inhibit AGE formation has recently been an objective of worldwide research ${ }^{(27,28)}$.

Dietary AGE/ALE have been described as a major contributor to the body AGE/ALE pool, which is associated with the development of different pathologies ${ }^{(29)}$. Consequently, the aim of the present review is to discuss how a so-called 'healthy eating behaviour' may help to reduce the AGE/ ALE pool (Fig. 2). In this sense, we propose the Healthy Eating Pyramid of the SENC and the Healthy Eating Plate proposed by Harvard University as recommendations for reducing dietary contribution to the body's AGE/ALE pool. These strategies involve recommendations for healthy nutrition (see Healthy foods and Healthy beverages sections) and the improvement of food quality (see Food Reformulation and Food processing and culinary practices sections) to reduce the rate of the Maillard reaction. All of them are shown in Fig. 3 and discussed in the following sections.

\section{Healthy nutrition}

\subsection{Healthy foods}

Dietary intake of foods with a high AGE content seems to predispose to inflammation and deteriorating biological effects, whereas AGE restriction may have an opposite, beneficial impact $^{(10)}$. AGE/ALE have been implicated in the pathogenesis of type 2 diabetes and a diet low in these compounds has been shown to improve insulin resistance in individuals with type 2 diabetes $^{(30)}$. To date, there are two databases with the content of CML measured by ELISA in more than 500 food items to know which foods possess high AGE content ${ }^{(31,32)}$. Takeuchi et al. ${ }^{(16)}$ have assessed by ELISA the concentrations of various AGE in beverages and foods that are commonly consumed in Japan. In addition, there is another more recent database based on data obtained by ultra-performance liquid chromatography-tandem $\mathrm{MS}^{(17)}$. Data on content of AGE in foods and beverages, determined using selective analytical methods for individual reaction products by several research groups, are publicly accessible at the web page of the Technical University of Dresden, Germany (https://lemchem.file3.wcms.tu-dresden. de//index.php). Altogether, these databases provide an overview of the presence of AGE/ALE in foods, the consumers' exposure to these compounds and they can be used as a guide for selecting the strategies for an effective reduction of their dietary intake.

Table 1 shows the content of carbohydrates, fat, MGO and AGE content of foods and beverages present in the Healthy Eating Pyramid and Plate (Fig. 3). Both healthy eating recommendations indicate which foods are healthier and how often they should be consumed. In addition, the pyramid (Fig. 3(a)) considers which culinary practices are more adequate for healthy nutrition. The plate (Fig. 3(b)) recommends drinking water and tea or coffee with no added sugar, and to avoid sugary drinks. These recommendations agree with those proposed by the SENC in their Healthy Hydration Pyramid ${ }^{(33)}$.

In general, the consumption of low-sugar and low-fat food reduces the availability of substrates of the Maillard reaction, leading to a lower contribution to the body's AGE/ALE pool. The European Food Safety Authority (EFSA) states that 'a claim that a food is low in sugars, and any claim likely to have the same meaning for the consumer, may only be made where the product contains no more than $5 \mathrm{~g}$ of sugars per $100 \mathrm{~g}$ for solids or $2.5 \mathrm{~g}$ of sugars per $100 \mathrm{ml}$ for liquids' and that 'a claim that a food is low in fat, and any claim likely to have 


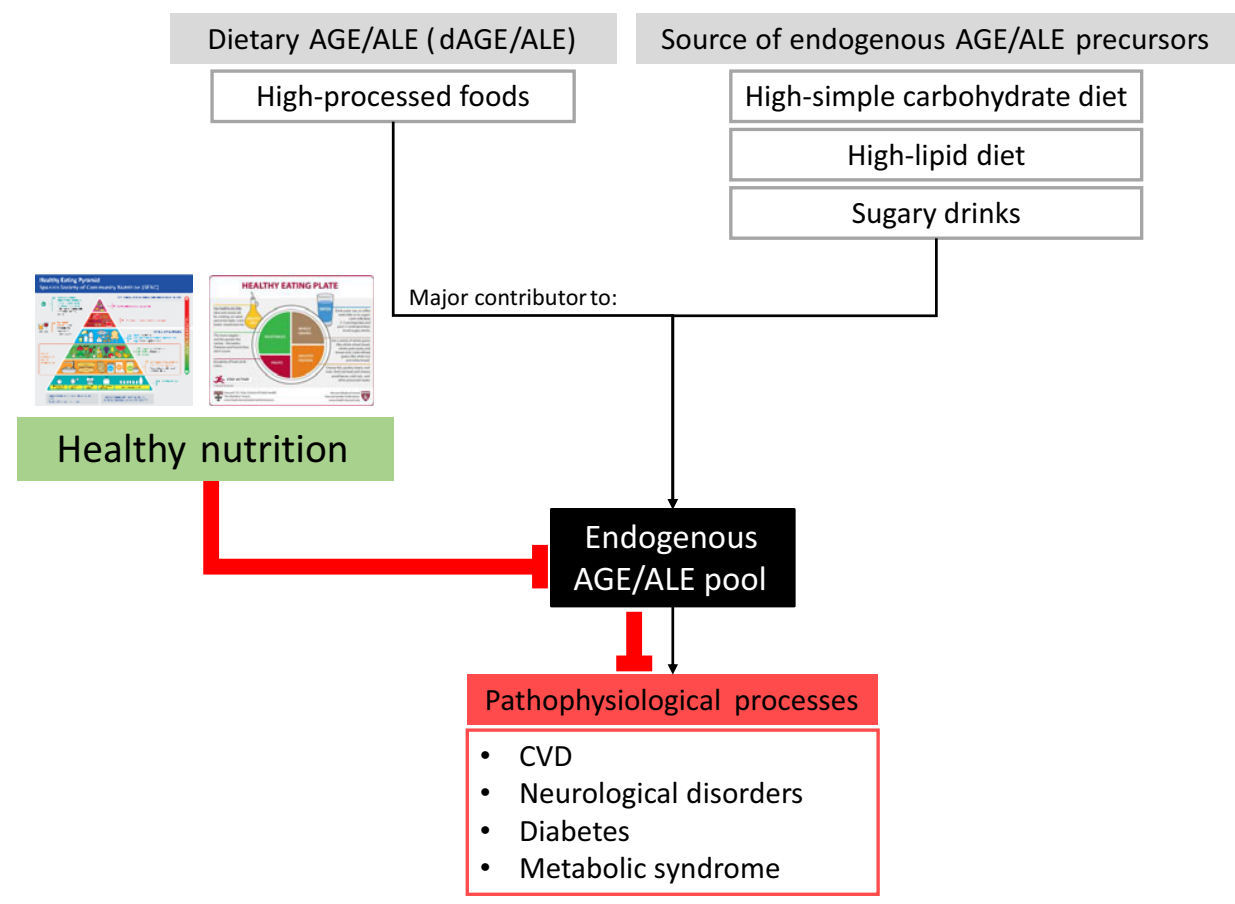

Fig. 2. Healthy nutrition for reducing the sources of advanced glycation/lipoxidation end product (AGE/ALE) precursors to reduce the risk of pathologies associated with their accumulation.

the same meaning for the consumer, may only be made where the product contains no more than $3 \mathrm{~g}$ of fat per $100 \mathrm{~g}$ for solids or $1.5 \mathrm{~g}$ of fat per $100 \mathrm{ml}$ for liquids $(1.8 \mathrm{~g}$ of fat per $100 \mathrm{ml}$ for semi-skimmed milk)'.

As can be observed in Table 1, foods rich in solid fats, fatty meats, full-fat dairy products and highly processed foods tend to be the richest dietary sources of $\mathrm{AGE}^{(20,34)}$; whereas low-fat foods containing complex and simple carbohydrates such as legumes, vegetables, fruits and whole grains and low-fat milk products tend to be relatively low in $\mathrm{AGE}^{(17)}$. These carbohydrate-rich foods possess low AGE content since they are composed of complex carbohydrates, mainly dietary fibre, which modulates carbohydrate metabolism, decreasing free sugar bioavailability that contributes to the formation of endogenous AGE. In addition, clinical trials have proved the effect of glycation inhibitor compounds (trans-resveratrol and hesperetin from grapes and citrus) that are present in vegetables and fruits ${ }^{(35)}$. Recently, further information on the hesperedin effect on glucose and fructose transport, sucrase activity and glycaemic response to orange juice in a cross-over trial on healthy volunteers has been published ${ }^{(25)}$. The intake of nutritional supplements or functional foods, which may contain glycation inhibitors and/or modulators of the glucose response, is recommended in the healthy diet proposed by the SENC (Fig. 3) ${ }^{(36)}$.

The bottom of the Heathy Eating Pyramid reported by SENC corresponds to foods recommended on a daily basis such as whole grains, fruits and vegetables and low-fat milk, which are foods with low AGE levels. A certain content of AGE/ALE is present in raw foods of animal and plant origin ${ }^{(4,16,17)}$. The amount of protein-bound CML or CEL in fruits, vegetables, butter, oils and some beverages is negligible or even under the detection limit of the ultra-performance liquid chromatographytandem MS (UPLC-MS/MS) method (Table 1) ${ }^{(17)}$. Takeuchi et $a l .{ }^{(16)}$ also found very low amounts of AGE in these foods when determined by ELISA. However, in raw meat the amounts of AGE/ALE adducts vary for different animal species, meat cut and meats of different suppliers. For instance, raw pork contains about $50 \%$ less free CML and CEL compared with beef; and in chicken meat, levels of free CML are about the same as in beef, while those of free CEL are on average 11-fold higher ${ }^{(37)}$.

On top of the pyramid there are candies, cookies, highly processed foods, such as packaged meats and snack-type foods; and fats, including butter, full-fat cheeses and fried foods, which are nor recommended and the intake of them should be moderate or restricted. Many commercially processed foods such as dry mixes or canned soups, which often contain larger amounts of protein and carbohydrates, undergo Maillard reaction during heat processing and they continue to brown during storage ${ }^{(32)}$. These guidelines recommended by the SENC are also consistent with recommendations by organisations such as the American Heart Association ${ }^{(38)}$, the American Institute for Cancer Research ${ }^{(39)}$ and the American Diabetes Association ${ }^{(40)}$.

Šebeková \& Brouder Šebeková ${ }^{(4)}$ have summarised the information so far published regarding the bioavailability of dietary AGE. Ames ${ }^{(3)}$ reported that up to $80 \%$ of dietary Amadori rearrangement products are not absorbed but are degraded by the gut microflora. However, the majority of the AGE in foods that are absorbed is rapidly excreted by the kidneys. Ames ${ }^{(3)}$ concluded there is no solid evidence obtained using human subjects for a positive relationship between the intake of dietary AGE and the up-regulation of pro-inflammatory markers or changes in the 
(a)

\section{Healthy Eating Pyramid Spanish Society of Community Nutrition (SENC)}

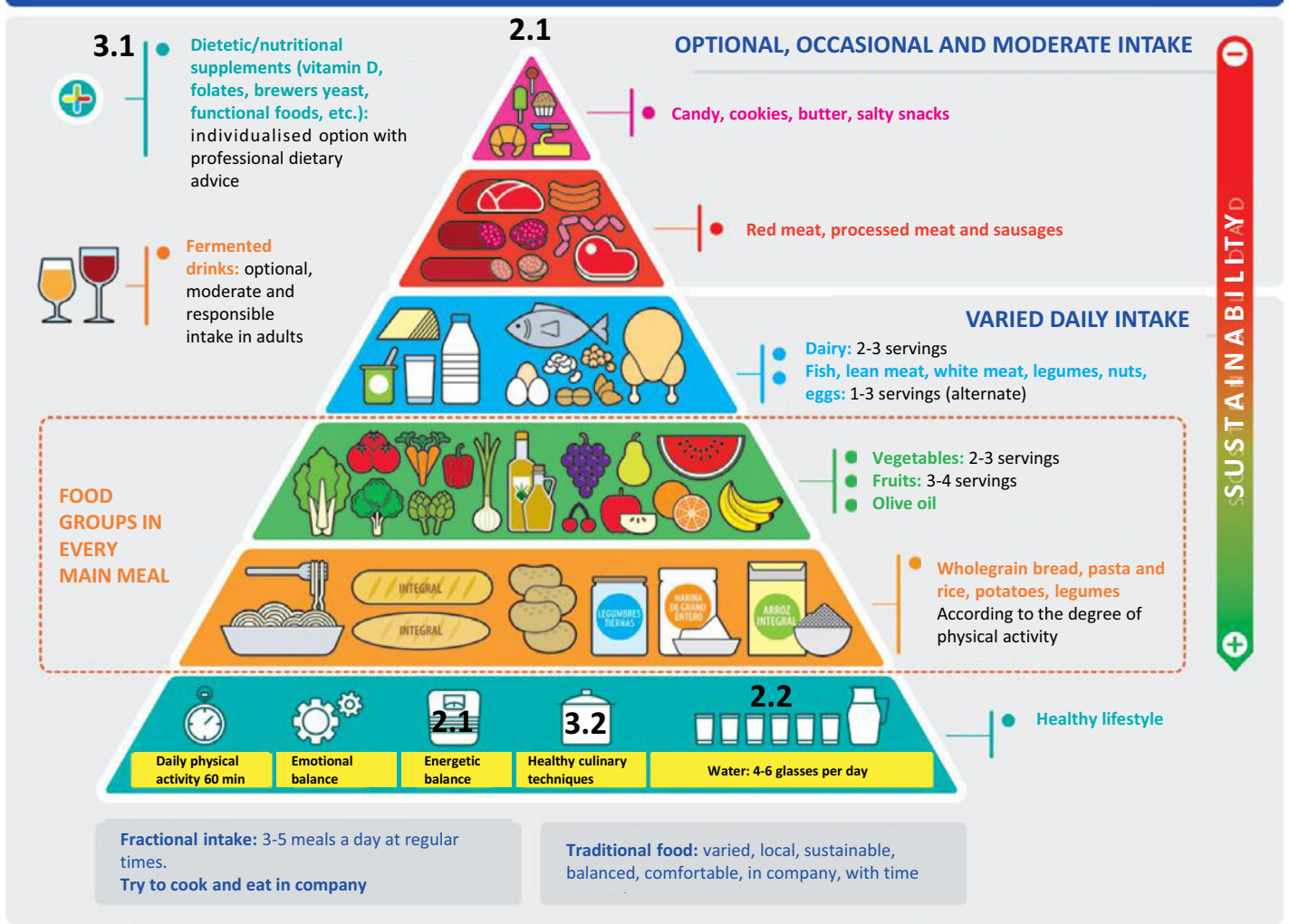

(b)

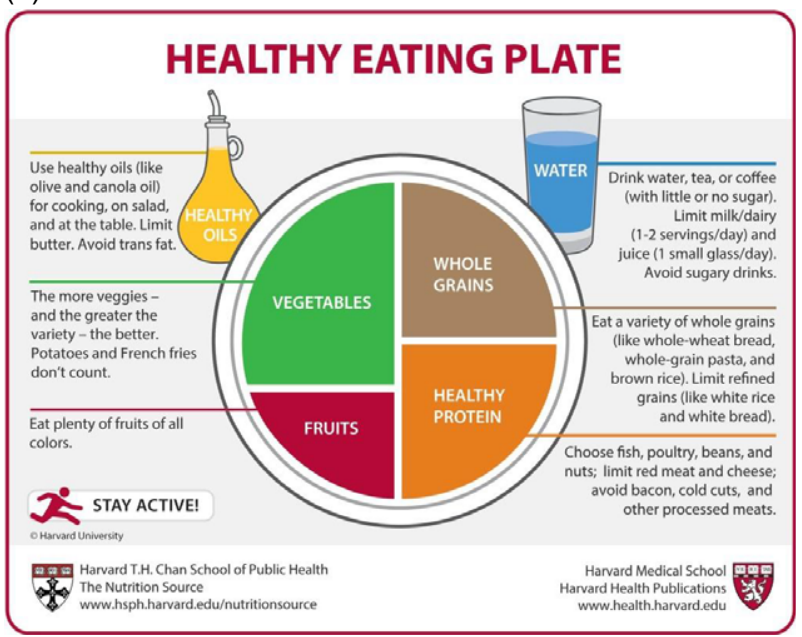

(c)
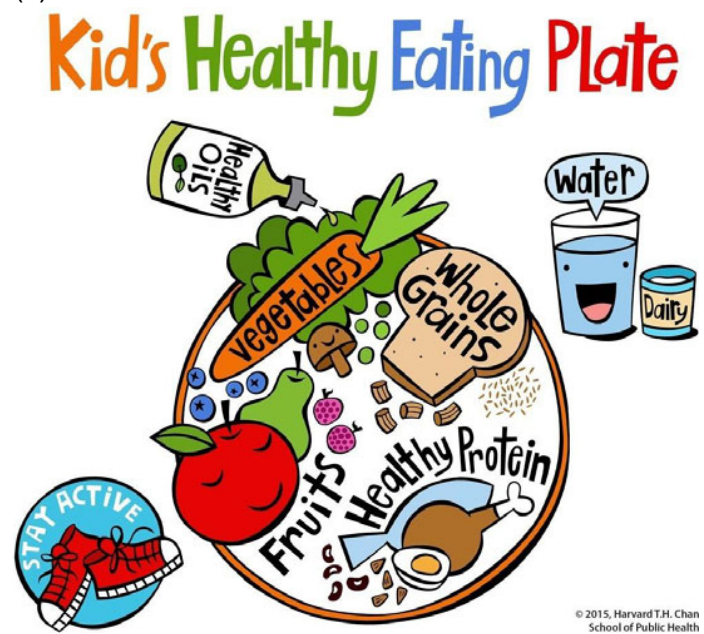

Fig. 3. Healthy eating recommendations: (a) the translated Healthy Eating Pyramid proposed by the Spanish Society of Community Nutrition (SENC, 2018), (b) the Healthy Eating Plate (Copyrighto 2011, Harvard University) and (c) The Kid's Healthy Eating Plate. The Harvard School of Public Health created both Healthy Eating Plates. Copyright $\odot 2015$ Harvard T.H. Chan School of Public Health. For more information about The Kid's Healthy Eating Plate, please see The Nutrition Source, Department of Nutrition, Harvard T.H. Chan School of Public Health (hsph.harvard.edu/nutritionsource/kids-healthy-eating-plate). Numbers in (a) and (b) indicate the different strategies proposed in the present review: 2.1 , healthy nutrition; 2.2, healthy hydration; 3.1 , food reformulation; and 3.2, culinary practices.

colonic microflora $^{(3)}$. On the other hand, Hellwig et al. ${ }^{(41)}$ have showed for the first time that Escherichia coli strains are able to degrade CML to defined metabolites with the biogenic amine $N$-carboxymethylcadaverine as the main product. Some clinical studies have demonstrated an effect of probiotics on early glycation since the glycated $\mathrm{Hb}(\mathrm{HbA} 1 \mathrm{c})$ content was decreased after a long-term exposure to Lactobacillus strains ${ }^{(42)}$. To the best of our knowledge, a protective effect of probiotics against the 
accumulation of AGE in the body has not been demonstrated. A pilot study performed by Yacoub et al. ${ }^{(43)}$ found that shortterm restriction of dietary AGE intake can significantly decrease circulating MGO and CML levels in renal failure patients on maintenance peritoneal dialysis and further suggested that this dietary intervention may have an effect on the gut microbiota. Dietary AGE restriction altered the bacterial gut microbiota with a significant reduction in Prevotella copri and Bifidobacterium animalis relative abundance and increased Alistipes indistinctus, Clostridium citroniae, Clostridium hathewayi, and Ruminococcus gauvreauii relative abundance $^{(43)}$. In rats the intake of dietary AGE reduced gut microbiota abundance and diversity, potentially because of their resistance to digestive enzymes, adversely altering gut microbiota composition. Dietary AGE increased protein fermentation and reduced the fermentation of carbohydrates, as evidenced by increased levels of the putrefactive toxic metabolites ammonia and branched-chain fatty acids at the expense of beneficial metabolites like SCFA ${ }^{(44)}$. There are mixed reports on the effects of high-AGE diets on the production of SCFA ${ }^{(45)}$. Furthermore, dietary AGE damaged the colonic epithelial barrier, enabling more endotoxins to enter the systemic circulation. These results should be taken into consideration in food processing and nutritional guidelines for modern individuals, especially in a situation in which high-temperature-produced fried and grilled foods are over-consumed. The healthy influences of dietary AGE on gut microbiota are still a matter of debate and larger studies are needed to confirm the effect of dietary AGE on the microbiota.

In summary, these are the main recommendations for a low-AGE/ALE diet:

(1) Be wary of browning.

(2) Eat as much varied natural fresh food as possible.

(3) Reduce the intake of highly processed food.

(4) Eat more foods with low glycaemic index and that are low in fat.

(5) Eat more often at home freshly prepared and minimally processed foods.

All these recommendations agree with those proposed in Fig. 3.

2.1.1. Healthy baby food. The previous recommendations are directed at the adult population. The Kid's Healthy Eating Plate guidelines adapted from Harvard's Healthy Eating Plate are shown in Fig. 3(c), which are in line with those proposed for adults $^{(46)}$. However, the body's AGE/ALE pool is already influenced by the dietary patterns adopted during infancy and may have an impact on the predisposition or susceptibility to particular non-communicable degenerative diseases in adulthood ${ }^{(47)}$. During the first months of life, newborns need a diet of breast milk or infant formula, which is followed by the incorporation of complementary baby foods. Both infant formulas and processed baby foods fall into the category of 'foods for specific groups, $^{(48)}$.

Infant formulas are cows' milk-based products, which are adapted to simulate the composition of human milk. Their nutritional value is compromised as some of their main components (the reducing saccharide lactose and whey proteins containing lysine residues) are precursors of Maillard reaction products $^{(49,50)}$. The industrial heat treatments of these foods to ensure microbiological safety and prolonged shelf life result in the formation of substantial amounts of $\mathrm{AGE}^{(51)}$. Their content exceeds those present in human breast milk up to $670-$ fold $^{(51-53)}$ and is dependent on the composition, processing, consistency (liquid, powdered) and type (hydrolysed, non-hydrolysed) of the infant formulas ${ }^{(47)}$. CML is the main Maillard reaction product found in infant formula, but several others have also been identified (CEL, pyrraline, pentosidine, oxalic acid monolysinylamide, MGH1, etc. ${ }^{(53)}$. Therefore, breast-feeding, either mother's own milk or banked donor milk, is highly recommended ${ }^{(54)}$.

Processed baby foods represent a wide range of food products intended to fulfil the particular requirements of infants while they are being weaned ${ }^{(48)}$. These include processed cereal-based foods, which have to be reconstituted with milk or other liquids, as well as puréed foods including a wide range of ingredients. AGE content in these foods largely depends on their composition, which defines the presence of Maillard reaction product precursors, and their industrial processing (thermal treatment and storage time). Bosch et $a l{ }^{(55)}$ identified the presence of CML (69-118 mg/100 g protein) in infant foods containing skimmed milk and mixed cereals after 9 months of storage at $37^{\circ} \mathrm{C}$. The incorporation of honey increases CML levels compared with only cerealmilk-based infant foods and those with added fruits ${ }^{(51,55)}$. Homogenised jarred foods based on proteins and vegetables are the main sources of the daily intake of the Maillard reaction product 5-hydroxymethylfurfural (HMF) in babies ${ }^{56}$. Consequently, it is recommended to feed babies with homemade foods freshly prepared and appropriately cooked ${ }^{56}$ (with low cooking temperatures, or adding phenolic antioxidants or acids to lower AGE levels).

\subsection{Healthy beverages}

The School of Public Health of Harvard University and the WHO have indicated that sugar-sweetened beverages are a major contributor to obesity and diabetes development ${ }^{(57,58)}$. Given the demonstrated adverse effects of such beverages on health and the lack of any health benefits ${ }^{(59)}$, there is overwhelming evidence to avoid their consumption for reducing the beverage contribution to the body's AGE/ALE pool, which is associated with the development of chronic diseases.

Data reported by Aragno \& Mastrocola ${ }^{(60)}$ suggest that the glycation process following high sugar intake may play a central role in the development of metabolic disturbances ${ }^{(60)}$. The most recent reports on the effects of high sugar consumption and dietderived AGE on human health suggest the need to limit the dietary sources of AGE, including added sugars, to prevent the development of metabolic diseases and related co-morbidities $(\text { Table } 1)^{(60)}$.

Fructose is widely employed as a sweetener in drinks. Fructose is one of the most rapid and effective glycating agents when compared with other sugars ${ }^{(60)}$. Previous studies showed a larger accumulation of CML in plasma, liver, muscle 
and hippocampus for mice fed a high-fructose diet compared with mice fed a standard diet ${ }^{(6)}$. Observational research found that the intake of food and beverage sources of high-fructose corn syrup (HFCS) were associated with elevated serum and urinary CML. The authors explained that one possible explanation is that the source of the elevated CML is the intestine, not the food $^{(61-63)}$. Foods and beverages with high fructose:glucose ratios (HFCS-sweetened foods and beverages, agave syrup, crystalline fructose, apple juice, and apple juice blends) may promote the intestinal in situ formation of readily absorbed, pro-inflammatory extracellular, newly identified, fructose-associated AGE, an overlooked source of immunogenic $\mathrm{AGE}^{(63)}$.

Dietary AGE are derived from numerous precursors; they include a broad range of compounds with different structures and molecular weights (Fig. 1) ${ }^{(16)}$. Table 1 provides data on AGE/ALE and their precursors in recommended beverages and in those that should be avoided for healthy nutrition and to decrease their contribution to the body's AGE/ALE pool. Takeuchi et al. ${ }^{(16)}$ assessed the concentrations of various AGE (glucose-derived AGE (Glu-AGE), fructose-derived AGE (Fru-AGE), CML and glyceraldehyde-derived AGE (GlycerAGE)) in a total of 1650 beverages and foods that are commonly consumed in Japan. The authors reported that Glu-AGE, FruAGE, CML and Glycer-AGE in the examined beverages exhibited concentrations of $>85,2-12,<3 \%$ and trace amounts, respectively. The results of their study indicated that some lactic acid bacteria beverages, carbonated drinks, sugar-sweetened fruit drinks, sports drinks, mixed fruit juices, confectionery (snacks), dried fruits, cakes, cereals and prepared foods contain markedly higher Glu-AGE levels than other classes of beverages and foods. The lactic acid bacteria beverages containing large amounts of Glu-AGE were all produced via processes in which HFCS and skimmed milk were mixed and reacted at high temperature. Moreover, beverages that contained artificial sweeteners and carbonated drinks displayed low levels of Glu-AGE ${ }^{(16)}$. Interestingly, tea and coffee did not contain many Glu-AGE or CML. According to the AGE database of the Technical University of Dresden, no CML was reported in brewed coffee while values of $7 \cdot 8-9 \cdot 0 \mathrm{mg} \mathrm{CML} / 100 \mathrm{~g}$ protein in roasted coffee were found. Scheijen et al. ${ }^{(17)}$ also found nil amounts of CML but $0.01 \mathrm{mg} \mathrm{CEL} / 100 \mathrm{~g}$ and $0.24 \mathrm{mg} \mathrm{MGH} 1 / 100 \mathrm{~g}$ in coffee. The daily intake of these beverages is recommended for healthy hydration (Fig. 3) and may contribute to the reduction of endogenous AGE/ALE accumulation because they can modulate the glycaemic response ${ }^{(25)}$.

In normal rats administered with Glu-AGE-rich beverages an increased hepatic receptor for AGE (RAGE) expression and the enhanced production/accumulation of Glycer-AGE and Glu-AGE were detected. The frequent intake of these beverages and foods may enhance the production/accumulation of GlycerAGE, leading to Glycer-AGE-RAGE interactions ${ }^{(64)}$. In human subjects, it has been demonstrated that roughly $10 \%$ of the AGE in foods and beverages are taken up into the body ${ }^{(65)}$. Care should be taken when mixing Glu-AGE-containing products or consuming large amounts of Glu-AGE-containing beverages or foods as this can result in elevated concentrations of Glu-AGE and sugar in the blood and promote the hepatic build-up of Glu-AGE ${ }^{(16)}$.
Despite the French paradox ${ }^{(66)}$ and the fact that moderate alcohol consumption is recommended within the Mediterranean diet (no more than two drinks per $\mathrm{d}$ for men or one drink per $\mathrm{d}$ for women) ${ }^{(33)}$, evidence shows that the ideal situation for health is to not drink at all ${ }^{(67)}$. Alcohol is closely related to about sixty different diagnoses and for almost all there is a close doseresponse relationship; so the more you drink, the higher your risk of disease ${ }^{(67)}$.

In addition, AGE and their precursors have also been found in the fermented alcoholic beverages highly consumed in Southern Europe. The main AGE present in beer are pyrraline $(0 \cdot 16-40 \cdot 00 \mathrm{mg} / \mathrm{l})$ and MG-H1 $(0 \cdot 3-13.7 \mathrm{mg} / \mathrm{l})^{(68)}$. This beverage also presents AGE precursors such as 3-DG (12.9-136.0 mg/l), among others ${ }^{(69)}$. In contrast, red wine presents negligible AGE content ${ }^{(17)}$ but $0.5-1.8 \mathrm{mg} / 1$ of $\mathrm{MGO}^{(70)}$.

On the other hand, a large number of plants contain bioactive compounds able to inhibit AGE formation in the human body and in processed foods ${ }^{(71)}$. Polyphenols (phenolic acids, flavonoids, stilbenes and lignans) constitute the major group of plant-derived compounds with anti-AGE activity ${ }^{(72-76)}$. Many in vitro experiments demonstrated that polyphenols can inhibit the biosynthesis of AGE through their antioxidant properties, metal-chelating ability, protein interaction, MGO trapping and/or blocking the RAGE ${ }^{(77,78)}$.

Tea, Camellia sinensis (Theaceae), the most consumed beverage after water, is an excellent source of flavonoids such as catechins. The most important catechins of green tea are: (-)-epicatechin (EC), (-)epicatechin-3-gallate (ECG), (-)-epigallocatechin (EGC) and (-)epigallocatechin-3-gallate (EGCG) ${ }^{(79)}$. Green tea consumption (drinking) significantly reduces the advanced glycation process, the accumulation of AGE and the cross-linking of tail tendon collagen in diabetes. Catechins have been investigated broadly on their bioactive properties such as anti-inflammation, anticancer and anti-obesity ${ }^{(80)}$. EGCG has demonstrated to be responsible for decreased AGE-stimulated gene expression, the production of TNF $\alpha$ and matrix metalloproteinase-13 (MMP-13) in human chondrocytes ${ }^{(81)}$. EGCG has also been shown to prevent intracellular AGE formation, trapping reactive dicarbonyl species such as MGO and GO that enhance the production of pro-inflammatory cytokines in monocytes. EGCG was able to attenuate LDL oxidation and glycation under high glucose conditions mimicking diabetes ${ }^{(82,83)}$. Tea also contains quercetin-3-O-rutinoside (rutin), a common dietary flavonoid that is an established antioxidant ${ }^{(84)}$. Gut microflora in the large intestine metabolise rutin to a variety of compounds that include quercetin and phenol derivatives with vicinal hydroxyl groups in their structure, such as 3,4-dihydroxyphenylacetic acid (DHPAA) and 3,4-dihydroxytoluene (DHT), which are powerful inhibitors of the formation of CML and fluorescent derivatives (370-440 and 335-385 nm) in histone H1 caused by ADP-ribose, a powerful glycating agent. The plasma concentrations of these rutin metabolites are expected to effectively neutralise the reported plasma concentrations of $\mathrm{GO}$ and $\mathrm{MGO}^{(85)}$. Rutin was also found to inhibit glucose-induced formation of glycation products in collagen type I in in vitro experiments and to be an effective inhibitor of lipoprotein glycation by increasing the resistance of LDL to high glucose and Cu-mediated oxidation $^{(86,87)}$. In addition, as previously mentioned, tea may not 
contain $\mathrm{AGE}^{(16)}$, being a healthy option for its daily intake and for the reduction of the endogenous AGE/ALE pool.

Coffee, Coffea arabiga (Rubiaceae), is also a beverage consumed worldwide. It contains phenolic compounds, mainly caffeoylquinic acids, $p$-coumaroylquinic, feruoylquinic and dicaffeoylquinic acids, which inhibit protein glycation and dicarbonyl compound formation. Chlorogenic acid (5-caffeoylquinic acid) in addition to other caffeoyl derivative polyphenols contributed to about $70 \%$ of the antioxidant capacity of a coffee extract $^{(88)}$. This compound, also found in the edible parts of some other plants, acts as an anti-AGE agent by metal chelation or by modulation of antioxidant enzyme gene expression ${ }^{(89)}$. Bioavailability studies carried out in human subjects have indicated that at least six intact major chlorogenic acid compounds are found in human plasma after acute coffee consumption and also that caffeoylquinic acid and dicaffeoylquinic acid isomers are probably differentially absorbed and/or metabolised. In addition, urine does not appear to be a major excretion pathway of intact chlorogenic acid compounds ${ }^{(90)}$. Moreover, studies carried out with green coffee samples have shown that the main chlorogenic acid compounds present in the green coffee matrix are also highly bioavailable in human subjects ${ }^{(91)}$. Therefore, chlorogenic acid present in coffee may be able to exert its antiglycative effect in human subjects after absorption. Moreover, Ishizakaa et al. ${ }^{(92)}$ analysed a large database of individuals who underwent general health screening, and found that coffee intake of three or more cups per $d$ was an independent negative correlate of oxidative stress in men, but not in women ${ }^{(92)}$. The in vivo antioxidant status associated with coffee consumption and its relation to disease morbidity and mortality need further investigations.

Mate tea, Ilex paraguariensis (Aquifoliaceae), is a South American beverage rich in caffeoyl derivative compounds. A marked inhibition of the formation of AGE and CML was demonstrated in in vitro model systems, which was associated with the presence of caffeic acid and chlorogenic acid ${ }^{(93)}$. Moreover, chlorogenic acid may interfere with glucose absorption ${ }^{(94)}$. It was also shown that extracts of Ilex paraguariensis were able to inhibit AGE-precursor formation in a similar way as synthetic AGE inhibitors, including aminoguanidine or carnosine ${ }^{(61)}$.

A study in Europe, covering the local plants used in water infusions as aromatic and refreshing hot beverages, showed that the most important plant families used to prepare recreational tea were Asteraceae and Lamiaceae. Tiliaceae had a leading position among the other families, with just a few species represented, showing its importance in European food culture. The majority of the top species are well known for their digestive properties, which is also one of the reasons cited for the selection of plants for teas to accompany meals ${ }^{(95)}$. The most important species according to their use were Thymus serpyllum L. and Melissa officinalis L. (Asteraceae); Achillea millefolium L., Chamaemelum nobile L., Matricaria chamomilla (Lamiaceae) and Tilia cordata (Tiliaceae). In addition, many of the same top species are also cited as having anti-inflammatory properties such as Thymus serpyllum, Achillea millefolium, Chamaemelum nobile and Tilia cordata ${ }^{(96)}$. Different polyphenols (phenolic acids and flavonoids) have been reported in Asteraceae and Tiliaceae. Apigenin glycosides, caffeoylquinic acid and ferulic acid have been reported in A. millefolium, luteolin glycosides and ferulic acid derivatives were reported in A. millefolium and C. nobile and kaempferol glycosides in T. $\operatorname{cordata}^{(97,98)}$. Among the flavonoids mentioned, apigenin and luteolin demonstrated their role as inhibitors of AGE formation in vitro ${ }^{(72)}$. Kaempferol is a well-known antioxidant that possesses anti-inflammatory activity. The short-term feeding of aged rats with this compound modulated both AGE accumulation and RAGE expression. Furthermore, kaempferol suppressed age-related NF- $\kappa \mathrm{B}$ activation and its pro-inflammatory genes through the suppression of AGE-induced NADPH oxidase activation $^{(99)}$. Among phenolic acids, ferulic acid showed antiglycative properties in a bovine serum albumin (BSA) assay ${ }^{(100)}$. This compound could bind to human serum albumin to form complexes, providing unusual protective effects against protein oxidation reducing the formation of CML and fluorescent AGE in vitro ${ }^{(101)}$.

The anti-AGE activity of Melissa officinalis extracts has been previously reported. This species contains rosmarinic acid, a dimmer of caffeic acid. The chaperone-like activity of this compound exerted a protective effect against AGE-induced toxicity by suppression of receptor signalling pathways, for example, RAGE antagonists ${ }^{(102)}$.

Topical application of extracts of banabá (Lagerstroemia speciosa), Chinese blackberry (Rubus suavissimus), kuma bamboo grass (Sasa veitchii) and persimmon leaf (Diospyros kaki) for 4 weeks prevented the increase of fluorescent AGE, and increased skin elasticity after 8 weeks ${ }^{(103)}$. Further investigation is necessary to determine if oral consumption of herbal teas affects skin. These herbal teas might be used in health foods and cosmetics designed as anti-ageing products for skin and body.

In conclusion, in agreement with the SENC and Harvard University recommendations (Fig. 3), drinking no-addedsugar beverages enriched with inhibitors of the Maillard reaction may be the one of the best nutritional strategies for reducing the formation and accumulation of AGE/ALE in the human body and related diseases.

\section{Improvement of food quality}

\subsection{Food reformulation}

A reduced intake of AGE/ALE and the decrease of their formation in the human body is necessary to reduce the risk of non-communicable chronic diseases, which may contribute to sustainable health of the global population ${ }^{(104)}$. This term was recently coined by del Castillo et al. ${ }^{(104)}$ and it is defined as: 'a healthy and active ageing avoiding the risk of diseases'. Formulation of dietetic nutritional supplements and novel foods, those called functional foods, is also a strategy for healthy eating, reducing the intake and the formation of AGE in the human body. The recommendations made by the SENC agree with this strategy since nutritional supplements and functional foods are proposed on top of the pyramid under professional advice (Fig. 3).

The EFSA defines food supplements as 'concentrated sources of nutrients (i.e. mineral and vitamins) or other substances with a nutritional or physiological effect that are marketed in 'dose' 
form (for example, pills, tablets, capsules, liquids in measured doses). A wide range of nutrients and other ingredients might be present in food supplements, including, but not limited to, vitamins, minerals, amino acids, essential fatty acids, fibre and various plants and herbal extracts'. Food supplements are intended to correct nutritional deficiencies, maintain an adequate intake of certain nutrients, or to support specific physiological functions. Guilbaud et al. ${ }^{(6)}$ propose probiotic supplementation since disruption of the microbiota can lead to physiological disorders and promote the development of some metabolic diseases. However, further studies are needed to study the potential protective effect of probiotics against the accumulation of AGE in the human body (see Healthy foods section).

The EFSA defines functional foods as: 'A food, which beneficially affects one or more target functions in the body, beyond adequate nutritional effects, in a way that is relevant to either an improved state of health and well-being and/or reduction of risk of disease. A functional food can be a natural food or a food to which a component has been added or removed by technological or biotechnological means, and it must demonstrate their effects in amounts that can normally be expected to be consumed in the diet'(105).

Bioactive compounds derived from vegetables and food waste have been examined for their activities to inhibit AGE formation and damage mediated by AGE. This activity was generally associated with the presence of polyphenols ${ }^{(106)}$. The potential of red grape skins recovered from winemaking processes as dietary anti-glycation agents preventing the glyco-oxidative stress associated with type 2 diabetes has been proposed. The anti-glycation potential was determined as the ability to inhibit the formation of AGE both in fructoseand in MGO-mediated protein glycation systems. In this study, for the grape skin extracts, $\mathrm{AGE}_{\mathrm{IC}} \mathrm{IC}_{50}$ values, inhibition of protein glycation by $50 \%$, were found to be between 9.2 and $15.0 \mu \mathrm{g}$ gallic acid equivalents (GAE)/ $\mathrm{ml}$ in the $\mathrm{BSA} /$ fructose model system and between 19.3 and $26 \cdot 1 \mu \mathrm{g} \mathrm{GAE} / \mathrm{ml}$ in the BSA/MGO model system. All grape skin samples showed similar anti-glycation ability evaluated with reference to GAE. The anti-glycation effectiveness of the studied samples was higher than that of commercial nutraceutical preparations ${ }^{(107)}$. The authors of the investigation concluded that in spite of differences in cultivar, location of the vineyard and winemaking procedures, these by-products could be used as a source of cost-effective anti-glycation agents either as food ingredients or as nutraceutical preparations. The possibility of using red grape skin extract for preventing AGE-mediated diabetic complications has also been reported by Jariyapamornkoon et al. ${ }^{(108)}$. In addition, the protective ability of phenolics from white grape vinification by-products against structural damage of BSA induced by glycation has been reported ${ }^{(109)}$. The anti-glycation activity of this by-product was measured by a BSA/fructose model system. Structural modifications of BSA were investigated by twodimensional isoelectric focusing sodium dodecyl sulfatePAGE (IEF/SDS-PAGE) and fluorescence measurements. The antiglycation activity ranged between 250 and $711 \mathrm{mmol}$ aminoguanidine $\mathrm{Eq} / \mathrm{kg}$. The in vitro MGO-trapping capacity of six red and seven white grape skin extracts obtained from winemaking by-products was also investigated. The trapping ability for red grape skin extracts correlated significantly with total phenolic content and antioxidant capacity. However, no correlations were observed for white grape skin extracts, which suggests that other compounds were involved in the trapping activity ${ }^{(110)}$. The effects of the addition of different ingredients and grape by-products to muffins on CML content have been studied by Mildner-Szkudlarz et al. ${ }^{(111)}$. Muffins enriched with grape by-products (20\%) showed lowering of CML level and no significant changes in the sensory profile. Grape by-products added to the model system with proteinrich ingredients resulted in the weakest inhibitory effects, probably due to the polyphenol-protein binding mechanism.

Naringenin, a flavanone that is the aglycone of narirutin present in citrus fruits and tomatoes, has been shown to inhibit glucose transport across the intestine in rats ${ }^{(25)}$. Teng et al. ${ }^{(112)}$ have evaluated how naringenin affects AGE formation in bread crust. They found that, with the increase in naringenin content in bread $(0 \cdot 25-1 \%, w / w)$, the formation of CML and total fluorescent AGE was significantly inhibited (9.67-54.27 and 11.79$35.19 \%$, respectively). Bread with naringenin showed a lower acrylamide content in bread crust, and enhanced antioxidant and antibacterial activities ${ }^{(112)}$. Similar results were found in bread with incorporation of quercetin $(1 \cdot 2,2.4 \text { and } 3.6 \%)^{(113)}$. Therefore, the use of these ingredients should be considered in the development of functional breads.

Olive mill wastewater is a by-product of the olive oil extraction processes with a high content of hydroxytyrosol, hydroxytyrosol derivatives and molecules containing o-dihydroxyl functions such as verbascoside. Studies have revealed that olive mill wastewater phenolic powder (OMW) is able to trap reactive carbonyl species such as hydroxycarbonyls and dicarbonyls; as well as to inhibit the formation of Amadori products and CML. As a consequence, OMW has been proposed as a functional ingredient able to control the Maillard reaction and to improve the nutritional and sensorial attributes of milk $^{(114)}$. The antiglycative capacity of olive mill wastewater was evaluated in vitro by BSAglucose and BSA-MGO assays, formation of Amadori products and direct trapping of reactive dicarbonyls ( $\mathrm{MGO}$ and $\mathrm{GO}$ ). Data confirmed that the direct trapping of dicarbonyl compounds is the main route explaining the antiglycative action rather than of the already known antioxidant capacity. Results support further investigations to evaluate the technological feasibility of using olive mill wastewater powders as antiglycative ingredients in foods or in pharmacological preparations in the future ${ }^{(115)}$.

The potential of an aqueous coffee silverskin extract (WO 2013/004873) on the pathogenesis of diabetes has been also investigated ${ }^{(116)}$. The bioactive compounds present in coffee silverskin extract affect several pathways involved in chronic diseases $^{(24)}$. They are able to inhibit in vitro AGE formation through the interaction of CGA and its derivatives with protein backbone ${ }^{(117)}$.

In addition, fermentation by-products as pineapple stem waste obtained during bromelain manufacturing process and buckwheat hull tea have also been described as inhibitors on the formation of $\mathrm{AGE}^{(118-120)}$.

The effect of sugarcane molasses extract (well-known source of phenolic compounds) on the formation of $\mathrm{CML}$ 
and CEL has been studied in glucose-lysine model reaction systems. This extract showed significant inhibitory effects. The antiglycative activities of sugarcane molasses extract was associated with its trapping abilities of reactive carbonyl species, such as GO and MGO. The authors emphasised the potential health effects of sugarcane molasses and the possibility of using byproducts as effective ingredients to reduce dietary Maillard reaction end products ${ }^{(121)}$

In vitro and in vivo studies have revealed that loss of antiglycative activity occurs in association with a decrease in phenolic compounds during digestion. Monteiro et al. ${ }^{(90)}$ evaluated the drug-kinetic profile in both human plasma and urine and the apparent bioavailability of chlorogenic acid from the ingestion of an extract of green decaffeinated coffee was close to $33 \%$. These results agree with those obtained in other in vivo studies by Olthof et al. ${ }^{(122)}$ who found that absorption of chlorogenic acid was 33 (sD 17) \% and of caffeic acid 95 (SD 4) \%. Preliminary results obtained by Medrano and co-workers (Xavier et $a l^{(123)}$ ) showed that the reduction in the phenolic compound content during studies of simulated digestion in extracts of blueberry (Vaccinium corymbosum) and Marcela (Achyrocline satureioides) correlated with antiglycative and antioxidant activities when confronting $\mathrm{OH}, \mathrm{OOH}$ and ABTS (2,2'-azino-bis(3-ethylbenzothiazoline-6-sulfonic acid)) radicals. Therefore, encapsulation may be a potential strategy to avoid this loss in antiglycative activity after in vivo digestion. Recent research has shown the feasibility of using liposomal encapsulation to protect phenolic compounds like quercetin. Encapsulation prevented quercetin degradation by $80 \%$ during storage ${ }^{(123)}$. Other research studied encapsulated green tea antioxidants in liposomes, which maintained the former's activity during digestion ${ }^{(124)}$. Rosmarinic acid and epigallocatechin gallate were found to have significant inhibitory effects when studied at different concentrations as natural inhibitors of Maillard browning in bakery rolls and applesauce $^{(125)}$. Consequently, the use of encapsulation would be a promising alternative for the incorporation of antiglycative compounds in nutraceuticals or functional foods.

Another strategy that should be considered in the reformulation of novel foods for a lower intake of dietary AGE is the reduction of sugar or fat content. In this sense, the reactants of the Maillard reaction would be less available. In 2004, the WHO challenged the private sector to improve the food supply and reduce levels of energy density, trans-fat, saturated fat, $\mathrm{Na}$ and added sugar in their products. A recent study showed that four disciplines are needed for food reformulation: Food Technology, Nutrition \& Health, Legislation and Consumer Perspectives $^{(126)}$. Reformulation by lowering the salt, saturated fat and sugar levels has a proven association with the reduction of the risk of chronic diseases ${ }^{(127)}$.

In summary, reformulation may be another strategy for the reduction of dietary AGE intake. The reduction of sugar and fat, and the addition of inhibitors from food by-products might be a possible strategy to achieve sustainable health ${ }^{(104)}$.

\subsection{Food processing and culinary practices}

The rate of formation and the diversity of generated AGE during food cooking also depend on food processing and culinary practices. CML levels in foods can be reduced by modifying the food processing parameters affecting the degree of progress of the Maillard reaction such as heating time, temperature and the type of cooking procedure, or using inhibitors during the culinary preparation ${ }^{(128)}$. Methods of water-based cooking processes, such as boiling and steaming, as well as shorter cooking times and lower cooking temperatures are recommended to achieve the goal.

Thermal processing is an important part of modern food preparation that can increase palatability, digestibility, reduces microbial content and prolongs shelf life. Heat, however, accelerates significantly the reaction between carbonyl groups and amino acids leading to the formation of numerous Maillard reaction product intermediates with different molecular sizes and composition $^{(129)}$. As a rule, the rate of the Maillard reaction at least doubles when the temperature is increased by $10^{\circ} \mathrm{C}^{(130)}$. Therefore, many actions can be easily taken to lower the dietary AGE consumption, particularly during cooking. In this sense, we should avoid preparing food with high heating temperature and long-time cooking by cooking methods such as grilling, frying, deep fat frying and roasting that are known to produce higher levels of AGE in food ${ }^{(32)}$. In contrast, methods of preparation that are water-based, such as boiling, and steaming, as well as shorter cooking times and lower cooking temperatures will tend to generate lower amounts of $\mathrm{AGE}^{(32)}$. The SENC also considers these culinary practices (Fig. 3) for healthy eating.

Scheijen et al. ${ }^{(17)}$ have found high AGE levels in food items which had been prepared by exposure to heat, industrial conserving or products containing chocolate, nuts or grains, whereas food products with short or no heat processing, low protein and/or carbohydrate content, or high water content had low or negligible AGE content. In their study, groundnuts, groundnut butter, rusk, biscuits, cereals, toast and high-heat-processed meats, such as red cooked beef, canned beef steak and black pudding, had the highest levels of CML and CEL, while coffee, fruits, vegetables, butter, olive oil and red wine had negligible AGE content ${ }^{(17)}$. Nuts, and particularly almonds, are sometimes consumed after roasting (which is typically between 140 and $180^{\circ} \mathrm{C}$ ). Roasting may cause changes to nut lipids and phytochemicals and generate AGE through the Maillard reaction ${ }^{(131)}$.

The presence of reactive dicarbonyls in food ingredients and heat-treated foods has been ascribed as an important contributor to AGE formation ${ }^{(132)}$. A body of evidence demonstrated that culinary processing promotes a higher level of dicarbonyls in processed foods when compared with that reported in raw materials $^{(133)}$. Processing at high temperatures triggers more dicarbonyl production, which in turn, also affects CML generation ${ }^{(134)}$.

Another factor that affects the rate of the Maillard reaction, as previously mentioned in the introduction, is water activity. Dehydration increases the contact and chemical reaction between food ingredients. Therefore, dry heat cooking has been found to promote formation of dietary AGE and the levels can be increased up to 100-fold above that found in uncooked food for most food categories ${ }^{(32)}$. Similarly, oxidation is also an important factor in increasing the CML production during food processing, being even more important than the change in the moisture content, as recently reported ${ }^{(135)}$. 
Another important factor affecting the formation of AGE is the initial $\mathrm{pH}$ of the reactants and the buffering capacity of the system, which influence both the rate and the direction of the pathway of the Maillard reaction. The rate of the Maillard reaction is considered to be low at acidic $\mathrm{pH}$ and being maximal when $\mathrm{pH}$ 10 is reached ${ }^{(128)}$. Therefore, AGE formation seems to be reduced by the use of acidic marinades such as lemon juice or $\operatorname{vinegar}^{(32)}$.

The cooking process can also influence other factors, which can in turn indirectly modulate AGE formation by modifying the concentrations of phytochemicals such as polyphenols (phenolic acids, flavonoids, stilbenes and lignans). They constitute the major group of plant-derived compounds with anti-AGE activity. For instance, culinary preparation plays a significant role in the final polyphenol content in processed foods, which can act as Maillard reaction inhibitors. The quercetin content of tomatoes and onions can be reduced by up to $80 \%$ from boiling, $65 \%$ from microwaving, and $30 \%$ from frying ${ }^{(136)}$. Furthermore, many components commonly found in foods such as guanidines, flavonoids and phenolic acids can serve as scavengers of the 1-2-dicarbonyl compounds such as MGO and GO, leading to a decrease in the amount of $\mathrm{AGE}^{(137-140)}$. In a sponge cake model, the authors tried to determine the effects of the addition of AGE/ALE inhibitors and different types of sugar and cooking oil on CML and CEL formation. Cakes baked using glucose produced the highest level of CML (2.07 (sD 0.24) mmol/mol lysine); cakes containing oil generated greater concentrations of CML than sucrose; whereas the cake baked using fructose produced the highest concentration of CEL (25.1 (sD 0.15) $\mathrm{mmol} / \mathrm{mol}$ lysine). The addition of ferulic acid and thiamin in cakes reduced CML and CEL formation ${ }^{(141)}$.

The presence of transition metals during cooking is also an important factor that contributes to AGE formation ${ }^{(142)}$. Although there is scarce or almost no information about the possible enhancer effect of metal cooking utensils in AGE formation, their generation might be facilitated when Cu utensils or those made with other metals are employed at high temperatures for a long period of time. Further research should be conducted.

In summary, the recommendations of culinary practices for low AGE formation, in foods for the adult population and for children, are as follows:

(1) Use of lower cooking temperatures rather than high cooking temperatures.

(2) Steaming, stewing and poaching are better cooking methods than frying, grilling and roasting.

(3) Phenolic antioxidants can inhibit the formation of AGE.

(4) Addition of acids (for example, vinegar, lemon juice) to food lowers AGE levels.

\section{Conclusions}

There is evidence supporting an important contribution of diet to the endogenous pool of AGE/ALE, which increases oxidative stress and inflammation and leads to the occurrence of chronic diseases such as diabetes and obesity. Therefore, we propose the Healthy Eating Pyramid and Plate as recommendations for the reduction of AGE/ALE in foods and their formation in the human body, which are as follows:

(1) Healthy nutrition

(a) Reduce the intake of highly processed food and eat more foods with low glycaemic index and low fat.

(b) Drink no-added-sugar beverages enriched with inhibitors of the Maillard reaction.

(2) Improvement of food quality

(a) Food reformulation: Reduction of sugar and fat, and the addition of inhibitors of the Maillard reaction and/or modulators of the glycaemic response such as phenols.

(b) Culinary practices: Steaming, stewing and poaching are recommended. Phenolic antioxidants and acids may be added to inhibit the formation of AGE/ALE during food preparation.

Recommendations should be considered in order to reduce the body's pool of AGE/ALE and the subsequent risk of noncommunicable chronic diseases.

\section{Acknowledgements}

This review was written on behalf of the Iberoamerican AGE Group: Rosana Filip (Argentina), Marisa Passarelli (Brazil), Sergio Salazar Villanea (Costa Rica), Armando Rojas Rubio, Ileana Gonzalez and Maria Pia de la Maza (Chile), Ma. Eugenia Garay-Sevilla, Armando Gomez Ojeda, Claudia Luevano Contreras, Maciste H. Macias Cervantes, Katarzyna Wrobel and Kazimierz Wrobel (Mexico), Manuel Portero-Otin and Ma. Dolores del Castillo (Spain), Alejandra Medrano (Uruguay) and Jaime Uribarri (USA). The authors thank the University of Guanajuato for holding the 3rd Iberoamerican Symposium of AGE, 'AGEs in nutrition and metabolic diseases and functional foods as anti-glycation agents' that took place from 24 to 26 October 2018 (http://agesenlasalud.com/).

The SUSCOFFEE (AGL 2014-57239-R) and ALIBIRD-CM (S2013/ABI-2728) projects funded the present review. The project 'Nuevos conocimientos para la sostenibilidad del sector cafetero' funded by CSIC (201970E117) also funded the present review.

There are no conflicts of interest.

\section{References}

1. Henle T (2007) Dietary advanced glycation end products - a risk to human health? A call for an interdisciplinary debate. Mol Nutr Food Res 51, 1075-1078.

2. Šebeková K \& Somoza V (2007) Dietary advanced glycation endproducts (AGEs) and their health effects - PRO. Mol Nutr Food Res 51, 1079-1084.

3. Ames JM (2007) Evidence against dietary advanced glycation endproducts being a risk to human health. Mol Nutr Food Res 51, 1085-1090.

4. Šebeková K \& Brouder Šebeková K (2019) Glycated proteins in nutrition: friend or foe? Exp Gerontol 117, 76-90.

5. Uribarri J, del Castillo MD, de la Maza MP, et al. (2015) Dietary advanced glycation end products and their role in health and disease. Adv Nutr 6, 461-473. 
6. Guilbaud A, Niquet-Leridon C, Boulanger E, et al. (2016) How can diet affect the accumulation of advanced glycation end-products in the human body? Foods 5, 84 .

7. Silván JM, van de Lagemaat J, Olano A, et al. (2006) Analysis and biological properties of amino acid derivates formed by Maillard reaction in foods. J Pharm Biomed Anal 41, 1543-1551.

8. Corzo-Martínez M, Corzo N, Villamiel M, et al. (2012) Browning reactions. In Food Biochemistry and Food Processing, 2nd ed., pp. 56-83 [BK Simpson, editor]. Oxford: Wiley-Blackwell.

9. Vistoli G, De Maddis D, Cipak A, et al. (2013) Advanced glycoxidation and lipoxidation end products (AGEs and ALEs): an overview of their mechanisms of formation. Free Radic Res 47, Suppl. 1, 3-27.

10. Palimeri S, Palioura A \& Diamanti-Kandarakis E (2015) Current perspectives on the health risks associated with the consumption of advanced glycation end products: recommendations for dietary management. Diabetes Metab Syndr Obes Targets Ther 8, 415-426.

11. Sadowska-Bartosz I \& Bartosz G (2015) Prevention of protein glycation by natural compounds. Molecules 20, 3309-3334.

12. Delgado-Andrade C \& Fogliano V (2018) Dietary advanced glycosylation end-products (dAGEs) and melanoidins formed through the Maillard reaction: physiological consequences of their intake. Annu Rev Food Sci Technol 9, 271-291.

13. Suh JH, Niu YS, Hung WL, et al. (2017) Lipidomic analysis for carbonyl species derived from fish oil using liquid chromatography-tandem mass spectrometry. Talanta 168, 31-42.

14. Tamanna N \& Mahmood N (2015) Food processing and Maillard reaction products: effect on human health and nutrition. Int J Food Sci 2015, 526762.

15. Nguyen HT, van der Fels-Klerx HJ \& van Boekel MAJS (2014) $N^{\varepsilon}$-(carboxymethyl)lysine: a review on analytical methods, formation, and occurrence in processed food, and health impact. Food Rev Int 30, 36-52.

16. Takeuchi M, Takino JI, Furuno S, et al. (2015) Assessment of the concentrations of various advanced glycation endproducts in beverages and foods that are commonly consumed in Japan. PLOS ONE 10, e0118652.

17. Scheijen JLJM, Clevers E, Engelen L, et al. (2016) Analysis of advanced glycation endproducts in selected food items by ultra-performance liquid chromatography tandem mass spectrometry: presentation of a dietary AGE database. Food Chem 190, 1145-1150.

18. Srey C, Haughey SA, Connolly L, et al. (2010) Immunochemical and mass spectrometric analysis of $\mathrm{Ne}$-(carboxymethyl)lysine content of AGE-BSA systems prepared with and without selected antiglycation agents. J Agric Food Chem 58, 11955-11961.

19. Gómez-Ojeda A, Jaramillo-Ortíz S, Wrobel K, et al. (2018) Comparative evaluation of three different ELISA assays and HPLC-ESI-ITMS/MS for the analysis of $N^{e}$-carboxymethyl lysine in food samples. Food Chem 243, 11-18.

20. Lopez-Moreno J, Quintana-Navarro GM, Camargo A, et al. (2017) Dietary fat quantity and quality modifies advanced glycation end products metabolism in patients with metabolic syndrome. Mol Nutr Food Res 61, 201601029.

21. Ejtahed HS, Angoorani P, Asghari G, et al. (2016) Dietary advanced glycation end products and risk of chronic kidney disease. J Ren Nutr 26, 308-314.

22. Kosmopoulos M, Drekolias D, Zavras PD, et al. (2019) Impact of advanced glycation end products (AGEs) signaling in coronary artery disease. Biochim Biophys Acta Mol Basis Dis 1865, 611-619.

23. Münch G, Westcott B, Menini T, et al. (2012) Advanced glycation endproducts and their pathogenic roles in neurological disorders. Amino Acids 42, 1221-1236.
24. Mesías M, Navarro M, Martínez-Saez N, et al. (2014) Antiglycative and carbonyl trapping properties of the water soluble fraction of coffee silverskin. Food Res Int 62, 1120-1126.

25. Kerimi A, Gauer JS, Crabbe S, et al. (2019) Effect of the flavonoid hesperidin on glucose and fructose transport, sucrase activity and glycaemic response to orange juice in a cross-over trial on healthy volunteers. Br J Nutr 121, 782-792.

26. Dueñas Martin M, Iriondo-DeHond A \& del Castillo MD (2018) Efecto de los compuestos fenólicos en el metabolismo de los carbohidratos (Effect of phenolic compounds on carbohydrate metabolism). Rev Española Nutr Comunitaria 24, 1-12.

27. Nagai R, Shirakawa J, Ohno R, et al. (2014) Inhibition of AGEs formation by natural products. Amino Acids 46, 261-266.

28. Starowicz M \& Zieliński H (2019) Inhibition of advanced glycation end-product formation by high antioxidant-leveled spices commonly used in European cuisine. Antioxidants 8, 100.

29. Clarke RE, Dordevic AL, Tan SM, et al. (2016) Dietary advanced glycation end products and risk factors for chronic disease: a systematic review of randomised controlled trials. Nutrients 8, 125.

30. Uribarri J, Cai W, Ramdas M, et al. (2011) Restriction of advanced glycation end products improves insulin resistance in human type 2 diabetes: potential role of AGER1 and SIRT1. Diabetes Care 34, 1610-1616.

31. Goldberg T, Cai W, Peppa M, et al. (2004) Advanced glycoxidation end products in commonly consumed foods. J Am Diet Assoc 104, 1287-1291.

32. Uribarri J, Woodruff S, Goodman S, et al. (2010) Advanced glycation end products in foods and a practical guide to their reduction in the diet. $J$ Am Diet Assoc 110, 911-916.e12.

33. Aranceta Bartrina J, Grupo Colaborativo de la Sociedad Española de Nutrición Comunitaria (SENC), Arija Val V, et al. (2016) Dietary guidelines for the Spanish population (SENC, December 2016); the new graphic icon of healthy food (article in Spanish). Nutr Hosp 33, Suppl. 8, 1-48.

34. Monnier VM (2007) Dietary advanced lipoxidation products as risk factors for human health - a call for data. Mol Nutr Food Res 51, 1091-1093.

35. Xue M, Weickert MO, Qureshi S, et al. (2016) Improved glycemic control and vascular function in overweight and obese subjects by glyoxalase 1 inducer formulation. Diabetes $\mathbf{6 5}$, 2282-2294

36. Sociedad Española de Nutrición Comunitaria (SENC) (2018) Guía de la alimentación saludable para la atención primaria $y$ colectivos cuidadanos (Guide to Healthy Eating for Primary Care and Groups of Citizens). Barcelona: SENC (Spanish Society of Community Nutrition).

37. Sun X, Tang J, Wang J, et al. (2016) Formation of free and protein-bound carboxymethyllysine and carboxyethyllysine in meats during commercial sterilization. Meat Sci 116, 1-7.

38. Lichtenstein AH, Appel LJ, Brands M, et al. (2006) Diet and lifestyle recommendations revision 2006: a scientific statement from the American Heart Association Nutrition Committee. Circulation 114, 82-96.

39. World Cancer Research Fund \& American Institute for Cancer Research (2007) Food, Nutrition, Physical Activity, and the Prevention of Cancer: A Global Perspective. Washington, DC: American Institute for Cancer Research.

40. American Diabetes Association (2008) Nutrition recommendations and interventions for diabetes: a position statement of the American Diabetes Association. Diabetes Care 31, Suppl. 1, S61-S78.

41. Hellwig M, Auerbach C, Müller N, et al. (2019) Metabolization of the advanced glycation end product $N$-e-carboxymethyllysine 
(CML) by different probiotic E. coli strains. J Agric Food Chem $\mathbf{6 7}$, 1963-1972.

42. Ejtahed HS, Mohtadi-Nia J, Homayouni-Rad A, et al. (2012) Probiotic yogurt improves antioxidant status in type 2 diabetic patients. Nutrition 28, 539-543.

43. Yacoub R, Nugent M, Cai W, et al. (2017) Advanced glycation end products dietary restriction effects on bacterial gut microbiota in peritoneal dialysis patients; a randomized open label controlled trial. PLOS ONE 12, e0184789.

44. Qu W, Yuan X, Zhao J, et al. (2017) Dietary advanced glycation end products modify gut microbial composition and partially increase colon permeability in rats. Mol Nutr Food Res 61, 1700118.

45. Snelson M \& Coughlan MT (2019) Dietary advanced glycation end products: digestion, metabolism and modulation of gut microbial ecology. Nutrients 11, 215.

46. Harvard T. H. Chan School of Public Health (2015) Kid's Healthy Eating Plate. Boston, MA: Harvard T. H. Chan School of Public Health Department of Nutrition.

47. Šebeková K, Simon Klenovics K \& Brouder Šebeková K (2014) Advanced glycation end products in infant formulas. In Handbook of Dietary and Nutritional Aspects of Bottle Feeding. Human Health Handbooks no. 8, pp. 421-440 [VR Preedy, RR Watson and S Zibadi, editors]. Wageningen: Wageningen Academic Publishers.

48. European Parliament and Council (2013) Regulation (EU) No 609/2013 on Food Intended for Infants and Young Children, Food for Special Medical Purposes, and Total Diet Replacement for Weight Control and Repealing Council Directive 92/52/EEC, Commission Directives 96/8/EC, 1999/21/EC, 2006/125/EC and 2006/141/EC, Directive 2009/39/EC of the European Parliament and of the Council and Commission Regulations (EC) No 41/ 2009 and (EC) No 953/2009. Off J Eur Union, L 181/35.

49. Contreras-Calderón J, Guerra-Hernández E \& GarcíaVillanova B (2008) Indicators of non-enzymatic browning in the evaluation of heat damage of ingredient proteins used in manufactured infant formulas. Eur Food Res Technol 227, $117-124$.

50. Li L, Han L, Fu Q, et al. (2012) Formation and inhibition of $N^{\epsilon}$-(carboxymethyl)lysine in saccharide-lysine model systems during microwave heating. Molecules 17, 12758-12770.

51. Birlouez-Aragon I, Pischetsrieder M, Leclère J, et al. (2004) Assessment of protein glycation markers in infant formulas. Food Chem 87, 253-259.

52. Šebeková K, Saavedra G, Zumpe C, et al. (2008) Plasma concentration and urinary excretion of $N^{e}$-(carboxymethyl)lysine in breast milk- and formula-fed infants. Ann N Y Acad Sci 1126, 177-180.

53. Pischetsrieder $M \&$ Henle $T$ (2012) Glycation products in infant formulas: chemical, analytical and physiological aspects. Amino Acids 42, 1111-1118.

54. Arnold LDW (2006) Global health policies that support the use of banked donor human milk: a human rights issue. Int Breastfeed J 1, 26

55. Bosch L, Sanz ML, Montilla A, et al. (2007) Simultaneous analysis of lysine, $N^{\epsilon}$-carboxymethyllysine and lysinoalanine from proteins. J Chromatogr B Anal Technol Biomed Life Sci 860, 69-77.

56. Calabretti A, Calabrese M, Campisi B, et al. (2017) Quality and safety in commercial baby foods. J Food Nutr Res 5, 587-593.

57. World Health Organization (2019) Reducing consumption of sugar-sweetened beverages to reduce the risk of childhood overweight and obesity. https://www.who.int/elena/titles/ ssbs_childhood_obesity/en/ (accessed February 2019).

58. Harvard T. H. Chan School of Public Health (2019) Sugary drinks and obesity fact sheet. https://www.hsph.harvard. edu/nutritionsource/sugary-drinks-fact-sheet/ (accessed February 2019).

59. Curhan GC \& Forman JP (2010) Sugar-sweetened beverages and chronic disease. Kidney Int 77, 569-570.

60. Aragno M \& Mastrocola R (2017) Dietary sugars and endogenous formation of advanced glycation endproducts: emerging mechanisms of disease. Nutrients $\mathbf{9}, 385$.

61. Gugliucci A \& Menini T (2002) The botanical extracts of Achyrocline satureoides and Ilex paraguariensis prevent methylglyoxal-induced inhibition of plasminogen and antithrombin III. Life Sci 72, 279-292.

62. Martinez-Saez N, Fernandez-Gomez B, Cai W, et al. (2019) In vitro formation of Maillard reaction products during simulated digestion of meal-resembling systems. Food Res Int 118, $72-80$.

63. DeChristopher LR (2017) Perspective: the paradox in dietary advanced glycation end products research - the source of the serum and urinary advanced glycation end products is the intestines, not the food. Adv Nutr 8, 679-683.

64. Sato T, Wu X, Shimogaito N, et al. (2009) Effects of high-AGE beverage on RAGE and VEGF expressions in the liver and kidneys. Eur J Nutr 48, 6-11.

65. Koschinsky T, He C-J, Mitsuhashi T, et al. (1997) Orally absorbed reactive glycation products (glycotoxins): an environmental risk factor in diabetic nephropathy. Med Sci $\mathbf{9 4}$, 6474-6479.

66. De Lorgeril M, Salen P, Paillard F, et al. (2002) Mediterranean diet and the French paradox: two distinct biogeographic concepts for one consolidated scientific theory on the role of nutrition in coronary heart disease. Cardiovasc Res 54, 503-515.

67. World Health Organization (2018). Q\&A - How can I drink alcohol safely? http://www.euro.who.int/en/health-topics/ disease-prevention/alcohol-use/data-and-statistics/q-and-ahow-can-i-drink-alcohol-safely (accessed April 2020).

68. Hellwig M, Witte S \& Henle T (2016) Free and protein-bound Maillard reaction products in beer: method development and a survey of different beer types. I Agric Food Chem 64, 7234-7243.

69. Rakete S, Klaus A \& Glomb MA (2014) Investigations on the Maillard reaction of dextrins during aging of pilsner type beer. J Agric Food Chem 62, 9876-9884.

70. Rodríguez-Cáceres MI, Palomino-Vasco M, Mora-Diez N, et al. (2015) Novel HPLC-fluorescence methodology for the determination of methylglyoxal and glyoxal. Application to the analysis of monovarietal wines "Ribera del Guadiana". Food Chem 187, 159-165.

71. Bahadoran Z, Mirmiran P \& Azizi F (2013) Dietary polyphenols as potential nutraceuticals in management of diabetes: a review. J Diabetes Metab Disord 12, 43.

72. Peng X, Ma J, Chen F, et al. (2011) Naturally occurring inhibitors against the formation of advanced glycation endproducts. Food Funct 2, 289-301.

73. Farsi DA, Harris CS, Reid L, et al. (2008) Inhibition of nonenzymatic glycation by silk extracts from a Mexican land race and modern inbred lines of maize (Zea mays). Phyther Res $\mathbf{2 2}$, 108-112.

74. Harris C, Beaulieu L-P, Fraser M-H, et al. (2011) Inhibition of advanced glycation end product formation by medicinal plant extracts correlates with phenolic metabolites and antioxidant activity. Planta Med 77, 196-204.

75. Ferchichi L, Derbré S, Mahmood K, et al. (2012) Bioguided fractionation and isolation of natural inhibitors of advanced glycation end-products (AGEs) from Calophyllum flavoramulum. Phytochemistry 78, 98-106.

76. Spencer JPE, Abd El Mohsen MM, Minihane A-M, et al. (2008) Biomarkers of the intake of dietary polyphenols: strengths, 
limitations and application in nutrition research. Br J Nutr $\mathbf{9 9}$, $12-22$.

77. Tan D, Wang Y, Lo C-Y, et al. (2008) Methylglyoxal: its presence and potential scavengers. Asia Pac J Clin Nutr 17, Suppl. 1, 261-264.

78. Chen H, Virk MS \& Chen F (2016) Phenolic acids inhibit the formation of advanced glycation end products in food simulation systems depending on their reducing powers and structures. Int J Food Sci Nutr 67, 400-411.

79. McKay DL \& Blumberg JB (2002) The role of tea in human health: an update. J Am Coll Nutr 21, 1-13.

80. Babu PVA, Sabitha KE \& Shyamaladevi CS (2008) Effect of green tea extract on advanced glycation and cross-linking of tail tendon collagen in streptozotocin induced diabetic rats. Food Chem Toxicol 46, 280-285.

81. Rasheed Z, Anbazhagan AN, Akhtar N, et al. (2009) Green tea polyphenol epigallocatechin-3-gallate inhibits advanced glycation end product-induced expression of tumor necrosis factor- $\alpha$ and matrix metalloproteinase-13 in human chondrocytes. Arthritis Res Ther 11, R71.

82. Peng X, Ma J, Chao J, et al. (2010) Beneficial effects of cinnamon proanthocyanidins on the formation of specific advanced glycation end products and methylglyoxal-induced impairment on glucose consumption. J Agric Food Chem $\mathbf{5 8}$ 6692-6696.

83. Wu C-H, Yeh C-T \& Yen G-C (2010) Epigallocatechin gallate (EGCG) binds to low-density lipoproteins (LDL) and protects them from oxidation and glycation under high-glucose conditions mimicking diabetes. Food Chem 121, 639-644.

84. Zhang R, Zhang B-L, He T, et al. (2016) Increase of rutin antioxidant activity by generating Maillard reaction products with lysine. Bioorg Med Chem Lett 26, 2680-2684.

85. Pashikanti S, de Alba DR, Boissonneault GA, et al. (2010) Rutin metabolites: novel inhibitors of nonoxidative advanced glycation end products. Free Radic Biol Med 48, 656-663.

86. Cervantes-Laurean D, Schramm DD, Jacobson EL, et al. (2006) Inhibition of advanced glycation end product formation on collagen by rutin and its metabolites. J Nutr Biochem 17, $531-540$

87. Wu C-H, Lin J-A, Hsieh W-C, et al. (2009) Low-density-lipoprotein (LDL)-bound flavonoids increase the resistance of LDL to oxidation and glycation under pathophysiological concentrations of glucose in vitro. J Agric Food Chem 57, 5058-5064.

88. Verzelloni E, Tagliazucchi D, Del Rio D, et al. (2011) Antiglycative and antioxidative properties of coffee fractions. Food Chem 124, 1430-1435.

89. Gugliucci A, Bastos DHM, Schulze J, et al. (2009) Caffeic and chlorogenic acids in Ilexparaguariensis extracts are the main inhibitors of AGE generation by methylglyoxal in model proteins. Fitoterapia 80, 339-344.

90. Monteiro M, Farah A, Perrone D, et al. (2007) Chlorogenic acid compounds from coffee are differentially absorbed and metabolized in humans. J Nutr 137, 2196-2201.

91. Farah A, Monteiro M, Donangelo CM, et al. (2008) Chlorogenic acids from green coffee extract are highly bioavailable in humans. J Nutr 2309-2315.

92. Ishizakaa Y, Yamakadoa M, Toda A, et al. (2013) Relationship between coffee consumption, oxidant status, and antioxidant potential in the Japanese general population. Clin Chem Lab Med 51, 1951-1959.

93. Tsuji-Naito K, Saeki H \& Hamano M (2009) Inhibitory effects of Chrysanthemum species extracts on formation of advanced glycation end products. Food Chem 116, 854-859.

94. Ho S-C, Wu S-P, Lin S-M, et al. (2010) Comparison of antiglycation capacities of several herbal infusions with that of green tea. Food Chem 122, 768-774.
95. Pardo de Santayana M, Blanco E \& Morales R (2005) Plants known as té in Spain: an ethno-pharmaco-botanical review. J Ethnopharmacol 98(1-2), 1-19.

96. Sõukand R, Quave CL, Pieroni A, et al. (2013) Plants used for making recreational tea in Europe: a review based on specific research sites. J Ethnobiol Ethnomed 9, 58.

97. Wagner H \& Bladt S (1996) Plant Drug Analysis: A Thin Layer Chromatography Atlas. Berlin and Heidelberg: SpringerVerlag.

98. Ali SI, Gopalakrishnan B \& Venkatesalu V (2017) Pharmacognosy, phytochemistry and pharmacological properties of Achillea millefolium L.: a review. Phyther Res 31, 1140-1161.

99. Kim JM, Lee EK, Kim DH, et al. (2010) Kaempferol modulates pro-inflammatory NF- $\mathrm{KB}$ activation by suppressing advanced glycation endproducts-induced NADPH oxidase. Age (Omaha) 32, 197-208.

100. Wu C-H, Yeh C-T, Shih P-H, et al. (2010) Dietary phenolic acids attenuate multiple stages of protein glycation and high-glucose-stimulated proinflammatory IL- $1 \beta$ activation by interfering with chromatin remodeling and transcription in monocytes. Mol Nutr Food Res 54, Suppl. 2, S127-S140.

101. Silván JM, Assar SH, Srey C, et al. (2011) Control of the Maillard reaction by ferulic acid. Food Chem 128, 208-213.

102. Miroliaei M, Khazaei S, Moshkelgosha S, et al. (2011) Inhibitory effects of lemon balm (Melissa officinalis, L.) extract on the formation of advanced glycation end products. Food Chem 129, 267-271.

103. Hori M, Yagi M, Nomoto K, et al. (2012) Inhibition of advanced glycation end product formation by herbal teas and its relation to anti-skin aging. Anti-Aging Med 9, 135-148.

104. del Castillo MD, Iriondo-DeHond A \& Martirosyan DM (2018) Are functional foods essential for sustainable health? Ann Nutr Food Sci 2, 1015.

105. European Parliament and Council (2006) The European Parliament and The Council of the European Union. Regulation (EC) No 1924/2006 of the European Parliament and of the Council on nutrition and health claims made on foods. Off J Eur Union 404, 9-25.

106. Lund MN \& Ray CA (2017) Control of Maillard reactions in foods: strategies and chemical mechanisms. J Agric Food Chem 65, 4537-4552.

107. Sri Harsha PSC, Gardana C, Simonetti P, et al. (2013) Characterization of phenolics, in vitro reducing capacity and anti-glycation activity of red grape skins recovered from winemaking by-products. Bioresour Technol 140, 263-268.

108. Jariyapamornkoon N, Yibchok-anun S \& Adisakwattana S (2013) Inhibition of advanced glycation end products by red grape skin extract and its antioxidant activity. $B M C$ Complement Altern Med 13, 171.

109. Sri Harsha PSC, Lavelli V \& Scarafoni A (2014) Protective ability of phenolics from white grape vinification by-products against structural damage of bovine serum albumin induced by glycation. Food Chem 156, 220-206.

110. Sri Harsha PS, Mesias M, Lavelli V, et al. (2016) Grape skin extracts from winemaking by-products as a source of trapping agents for reactive carbonyl species. J Sci Food Agric 96, 656-663.

111. Mildner-Szkudlarz S, Siger A, Szwengiel A, et al. (2015) Natural compounds from grape by-products enhance nutritive value and reduce formation of CML in model muffins. Food Chem 172, 78-85.

112. Teng J, Li Y, Yu W, et al. (2018) Naringenin, a common flavanone, inhibits the formation of AGEs in bread and attenuates AGEs-induced oxidative stress and inflammation in RAW264.7 cells. Food Chem 269, 35-42. 
113. Lin J, Gwyneth Tan YX, Leong LP, et al. (2018) Steamed bread enriched with quercetin as an antiglycative food product: its quality attributes and antioxidant properties. Food Funct 9 , 3398-3407.

114. Troise AD, Fiore A, Colantuono A, et al. (2014) Effect of olive mill wastewater phenol compounds on reactive carbonyl species and Maillard reaction end-products in ultrahightemperature-treated milk. J Agric Food Chem 62, 10092-10100.

115. Navarro M, Fiore A, Fogliano V, et al. (2015) Carbonyl trapping and antiglycative activities of olive oil mill wastewater. Food Funct 6, 574-583.

116. Iriondo-DeHond A, Fernandez-Gomez B, Martínez-Sáez N, et al. (2017) Coffee silverskin : a low-cost substrate for bioproduction of high-value health promoting products. Ann Nutr Food Sci 1, 1005

117. Fernandez-Gomez B, Ullate M, Picariello G, et al. (2015) New knowledge on the antiglycoxidative mechanism of chlorogenic acid. Food Funct 6, 2081-2090.

118. Ye X-J, Ng TB \& Nagai R (2010) Inhibitory effect of fermentation byproducts on formation of advanced glycation endproducts. Food Chem 121, 1039-1045.

119. Upadhyay A, Chompoo J, Araki N, et al. (2012) Antioxidant, antimicrobial, 15-LOX, and AGEs inhibitions by pineapple stem waste. J Food Sci 77, H9-H15.

120. Zielinska D, Szawara-Nowak D \& Zielinski H (2013) Antioxidative and anti-glycation activity of buckwheat hull tea infusion. Int J Food Prop 16, 228-239.

121. Yu P, Xu X-B \& Yu S-J (2017) Inhibitory effect of sugarcane molasses extract on the formation of $N^{e}$-(carboxymethyl)lysine and $N^{e}$-(carboxyethyl)lysine. Food Chem 221, 1145-1150.

122. Olthof MR, Hollman PCH \& Katan MB (2001) Chlorogenic acid and caffeic acid are absorbed in humans. J Nutr 131, 66-71.

123. Xavier, MP, Miraballes I, Pardo H, et al. (2011) Encapsulación de quercetina en nano y micro-emulsiones alimenticias (Quercetin encapsulation in food nano and micro-emulsions). Revista del Laboratorio Tecnológico del Uruguay (INNOTEC) 2011, 37-41.

124. Rashidinejad A, Birch EJ, Sun-Waterhouse D, et al. (2016) Effect of liposomal encapsulation on the recovery and antioxidant properties of green tea catechins incorporated into a hard low-fat cheese following in vitro simulated gastrointestinal digestion. Food Bioprod Process 100, 238-245.

125. Favreau-Farhadi N, Pecukonis L \& Barrett A (2015) The inhibition of Maillard browning by different concentrations of rosmarinic acid and epigallocatechin-3-gallate in model, bakery, and fruit systems. J Food Sci 80, C2140-C2146.

126. van Gunst A, Roodenburg A \& Steenhuis I (2018) Reformulation as an integrated approach of four disciplines: a qualitative study with food companies. Foods 7, 64 .

127. World Health Organization (2003) Diet, Nutrition and the Prevention of Chronic Diseases: Report of the Joint WHO/ FAO Expert Consultation. WHO Technical Report Series no. 916. Geneva: WHO.
128. Sharma C, Kaur A, Thind SS, et al. (2015) Advanced glycation end-products (AGEs): an emerging concern for processed food industries. J Food Sci Technol 52, 7561-7576.

129. Poulsen MW, Hedegaard RV, Andersen JM, et al. (2013) Advanced glycation endproducts in food and their effects on health. Food Chem Toxicol 60, 10-37.

130. Nursten HE (1990) New aspects of the Maillard reaction in foods. Angew Chemie 29, 565-594.

131. Zhang G, Huang G, Xiao L, et al. (2011) Determination of advanced glycation end products by LC-MS/MS in raw and roasted almonds (Prunus dulcis). J Agric Food Chem 59, 12037-12046.

132. Degen J, Hellwig M \& Henle T (2012) 1,2-Dicarbonyl compounds in commonly consumed foods. J Agric Food Chem 60, 7071-7079.

133. Lingnert H, Grivas S, Jägerstad M, et al. (2002) Acrylamide in food: mechanisms of formation and influencing factors during heating of foods. Scand J Nutr 46, 159-172.

134. Nguyen HT, van der Fels-Klerx HJ \& van Boekel MAJS (2016) Kinetics of $N^{\varepsilon}$-(carboxymethyl)lysine formation in aqueous model systems of sugars and casein. Food Chem 192, $125-133$.

135. Xu R, Yue L, Kang S, et al. (2015) Assessment of the concentration of advanced glycation end products in traditional Chinese foods. J Food Process Preserv 41, e12811.

136. Pandey KB \& Rizvi SI (2009) Plant polyphenols as dietary antioxidants in health and disease. Oxid Med Cell Longev 2, 270-278.

137. Thornalley PJ (2003) Use of aminoguanidine (Pimagedine) to prevent the formation of advanced glycation endproducts. Arch Biochem Biophys 419, 31-40.

138. Joglekar MM, Panaskar SN \& Arvindekar AU (2014) Inhibition of advanced glycation end product formation by cymene - a common food constituent. J Funct Foods 6, 107-115.

139. Lo C-Y, Li S, Tan D, et al. (2006) Trapping reactions of reactive carbonyl species with tea polyphenols in simulated physiological conditions. Mol Nutr Food Res 50 , 1118-1128.

140. Peng X, Cheng K-W, Ma J, et al. (2008) Cinnamon bark proanthocyanidins as reactive carbonyl scavengers to prevent the formation of advanced glycation end products. J Agric Food Chem 56, 1907-1911.

141. Srey C, Hull GLJ, Connolly L, et al. (2010) Effect of inhibitor compounds on $N^{\epsilon}$-(carboxymethyl)lysine (CML) and $N^{\varepsilon_{-}}$ (carboxyethyl)lysine (CEL) formation in model foods. J Agric Food Chem 58, 12036-12041.

142. Corrales Escobosa AR, Wrobel K, Yanez Barrientos E, et al. (2015) Effect of different glycation agents on Cu(II) binding to human serum albumin, studied by liquid chromatography, nitrogen microwave-plasma atomic-emission spectrometry, inductively-coupled-plasma mass spectrometry, and highresolution molecular-mass spectrometry. Anal Bioanal Chem 407, 1149-1157. 